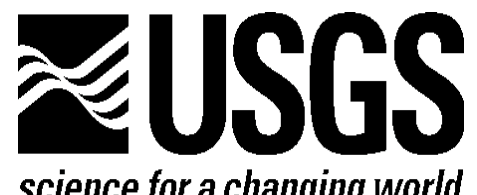

science for a changing world

Prepared for the

Federal Emergency Management Agency, Region 1, and the

Maine Floodplain Management Program, State Planning Office

\title{
Scoping of Flood Hazard Mapping Needs for Somerset County, Maine
}

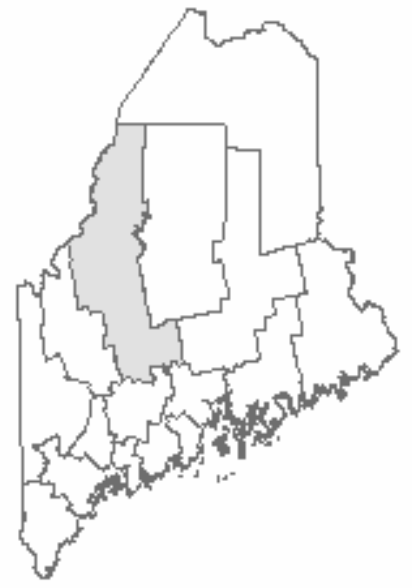

Open-File Report 2006-1100

U.S. Department of the Interior

U.S. Geological Survey

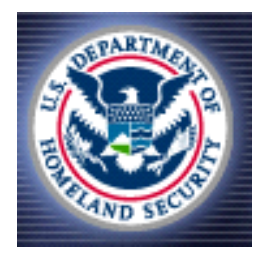


Prepared for the

Federal Emergency Management Agency, Region 1, and the

Maine Floodplain Management Program, State Planning Office

\section{Scoping of Flood Hazard Mapping Needs for Somerset County, Maine}

By Robert W. Dudley and Charles W. Schalk

Open-File Report 2006-1100

U.S. Department of the Interior

U.S. Geological Survey 


\section{U.S. Department of the Interior \\ Gale A. Norton, Secretary}

U.S. Geological Survey

P. Patrick Leahy, Acting Director

U.S. Geological Survey, Reston, Virginia 2006

For product and ordering information:

World Wide Web: http://www.usgs.gov/pubprod

Telephone: 1-888-ASK-USGS

For more information on the USGS - the Federal source for science about the Earth, its natural and living resources, natural hazards, and the environment:

World Wide Web: http://www.usgs.gov

Telephone: 1-888-ASK-USGS

Suggested citation:

Dudley, R.W., and Schalk, C.W., 2006, Scoping of flood hazard mapping needs for Somerset County, Maine: U.S. Geological Survey Open-File Report 2006-1100, 131 p.

Any use of trade, product, or firm names is for descriptive purposes only and does not imply endorsement by the U.S. Government.

Although this report is in the public domain, permission must be secured from the individual copyright owners to reproduce any copyrighted material contained within this report. 


\section{Contents}

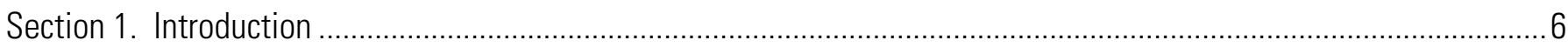

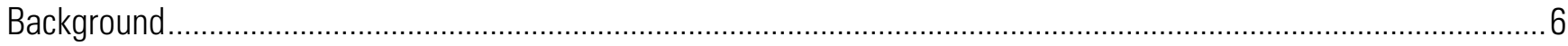

Scope of Work

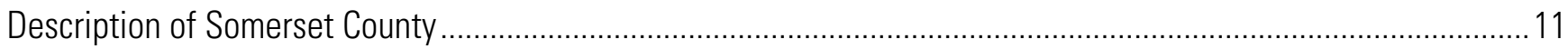

Section 2. Available Flood-Mapping Data and Mapping Needs............................................................................. 16

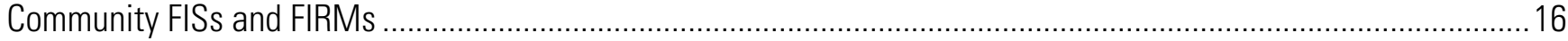

State of Maine Best Available Data (BAD) for Unnumbered A-Zones ................................................................ 16

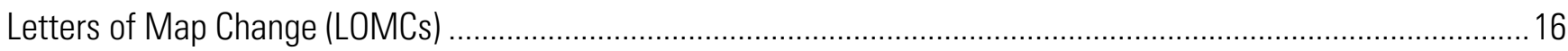

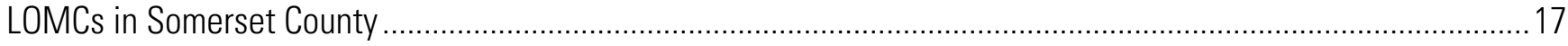

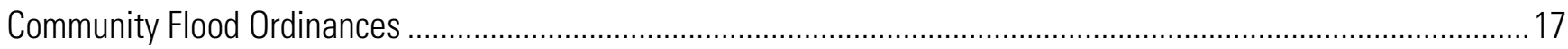

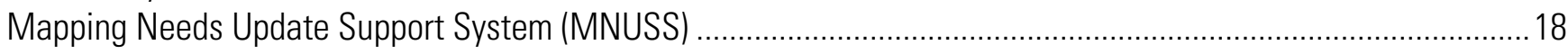

Community Assistance Visits (CAVs) and Community Assessment Contacts (CACs) .............................................18

GIS Data

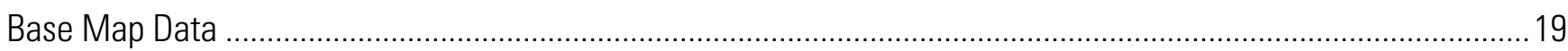

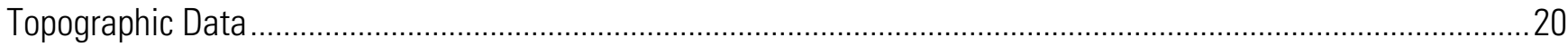

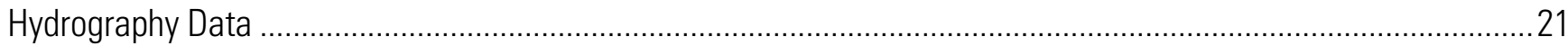

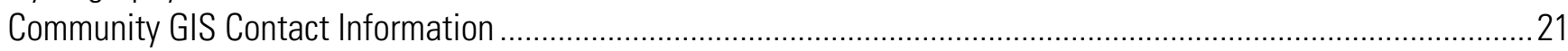

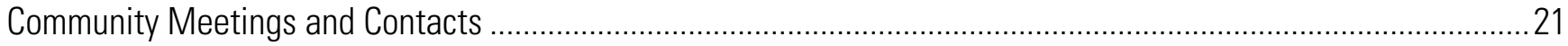

Scope and Prioritization of Mapping Needs in Somerset County .......................................................................22

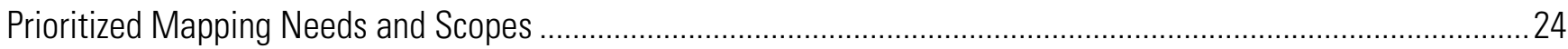

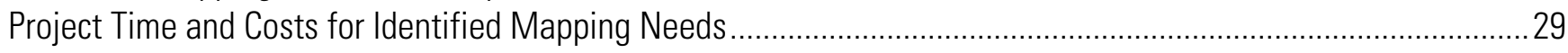

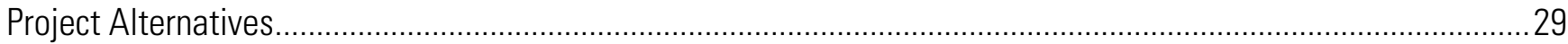

Section 3. Options for Future Mapping and DTM Preparation......................................................................... 30

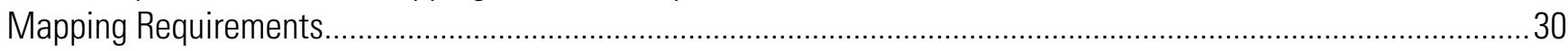

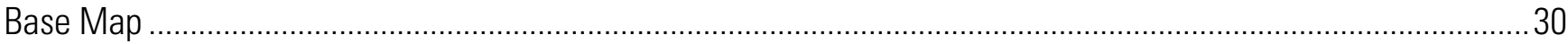

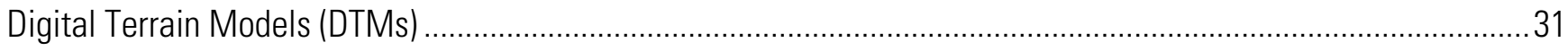

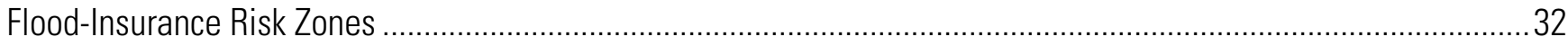

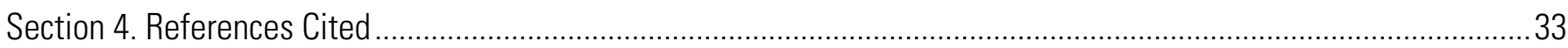

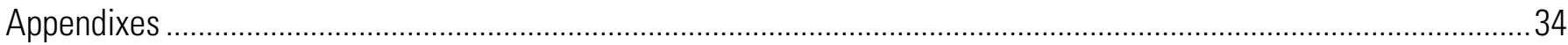

Appendix A: Community Assistance Contacts and Visits: Somerset County ............................................................... 35

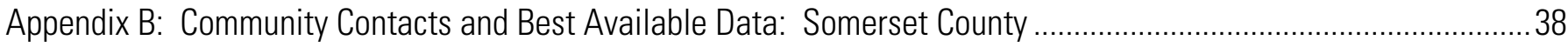

Appendix C: Community Scoping Interview Data: Somerset County...........................................................................69

Appendix D: Existing MNUSS Data Entries: Somerset County ............................................................................... 93

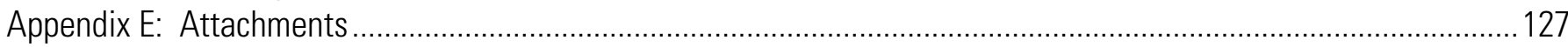

\section{Figures}

1. Communities and unorganized territories in (southern) Somerset County, Maine.....................................................12

2. Communities and unorganized territories in (northern) Somerset County, Maine.......................................................13

3. Hydrology of (southern) Somerset County, Maine................................................................................... 14

4. Hydrology of (northern) Somerset County, Maine..................................................................................... 15

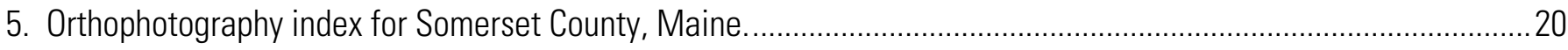

6. Mapping needs by community in Somerset County.Project time and costs fo identified mapping needs..................28 


\section{Tables}

1. Organized communities and unorganized territories in Somerset County, Maine.

2. Maine Floodplain Management Program factors and qualitative weight for prioritization of community-based flood mapping needs in Somerset County. 23

3. Scoring formula for prioritization of community-based flood mapping needs in Somerset County. 25

4. Prioritized community-based flood mapping needs in Somerset County requiring redelineation, limited detail study, or detail study.

5. Prioritized community-based flood mapping need in Somerset County on the basis of nonrevised baseline-

DFIRM production only.

6. Flood Insurance Rate Map (FIRM) Horizontal Accuracy.

7. National Standard for Spatial Data Accuracy (NSSDA).

CONVERSION FACTORS AND ABBREVIATIONS

\begin{tabular}{|c|c|c|}
\hline Multiply & By & To obtain \\
\hline \multicolumn{3}{|c|}{ Length } \\
\hline inch (in.) & 25.4 & millimeter (mm) \\
\hline foot $(\mathrm{ft})$ & 0.3048 & meter $(\mathrm{m})$ \\
\hline mile (mi) & 1.609 & kilometer (km) \\
\hline \multicolumn{3}{|c|}{ Area } \\
\hline square foot $\left(\mathrm{ft}^{2}\right)$ & 0.09290 & square meter $\left(\mathrm{m}^{2}\right)$ \\
\hline square mile $\left(\mathrm{mi}^{2}\right)$ & 2.590 & square kilometer $\left(\mathrm{km}^{2}\right)$ \\
\hline \multicolumn{3}{|c|}{ Volume } \\
\hline cubic foot $\left(\mathrm{ft}^{3}\right)$ & 0.02832 & cubic meter $\left(\mathrm{m}^{3}\right)$ \\
\hline \multicolumn{3}{|c|}{ Slope } \\
\hline foot per mile (ft/mi) & 0.1894 & meter per kilometer $(\mathrm{m} / \mathrm{km})$ \\
\hline \multicolumn{3}{|c|}{ Velocity and Flow } \\
\hline foot per second (ft/s) & 0.3048 & meter per second $(\mathrm{m} / \mathrm{s})$ \\
\hline cubic foot per second $\left(\mathrm{ft}^{3} / \mathrm{s}\right)$ & 0.02832 & cubic meter per second $\left(\mathrm{m}^{3} / \mathrm{s}\right)$ \\
\hline
\end{tabular}

OTHER ABBREVIATIONS USED IN REPORT

$\begin{array}{ll}\text { CAC } & \text { Community Assistance Contact } \\ \text { CAV } & \text { Community Assistance Visit } \\ \text { DFIRM } & \text { Digital Flood Insurance Rate Map } \\ \text { FEMA } & \text { Federal Emergency Management Agency } \\ \text { FIS } & \text { Flood Insurance Study } \\ \text { MEGIS } & \text { Maine Office of Geographic Information Systems } \\ \text { NFIP } & \text { National Flood Insurance Program } \\ \text { USGS } & \text { United States Geological Survey }\end{array}$




\title{
Scoping of Flood Hazard Mapping Needs for Somerset County, Maine
}

\author{
By Robert W. Dudley and Charles W. Schalk
}

\section{Section 1. Introduction}

This report was prepared by the U.S. Geological Survey (USGS) Maine Water Science Center as the deliverable for scoping of flood hazard mapping needs for Somerset County, Maine, under Federal Emergency Management Agency (FEMA) Inter-Agency Agreement Number HSFE01-05-X-0018. This section of the report explains the objective of the task and the purpose of the report.

\section{Background}

The Federal Emergency Management Agency (FEMA) developed a plan in 1997 to modernize the FEMA flood mapping program. FEMA flood maps delineate flood hazard areas in support of the National Flood Insurance Program (NFIP). FEMA's plan outlined the steps necessary to update FEMA's flood maps for the nation to a seamless digital format and streamline FEMA's operations in raising public awareness of the importance of the maps and responding to requests to revise them. The modernization of flood maps involves conversion of existing information to digital format and integration of improved flood hazard data as needed. To determine flood mapping modernization needs, FEMA has established specific scoping activities to be done on a county-by-county basis for identifying and prioritizing requisite flood-mapping activities for map modernization. The U.S. Geological Survey (USGS), in cooperation with FEMA and the Maine State Planning Office Floodplain Management Program, began scoping work in 2005 for Somerset County. Scoping activities included assembling existing data and map needs information for communities in Somerset County (efforts were made to not duplicate those of pre-scoping completed in March 2005), documentation of data, contacts, community meetings, and prioritized mapping needs in a final scoping report (this document), and updating the Mapping Needs Update Support System (MNUSS) Database or its successor with information gathered during the scoping process.

The average age of the FEMA floodplain maps in Somerset County, Maine is 18.1 years. Most of these studies were in the late 1970's to the mid 1980s. However, in the ensuing 20-30 years, development has occurred in many of the watersheds, and the characteristics of the watersheds have changed with time. Therefore, many of the older studies may not depict current conditions nor accurately estimate risk in terms of flood heights. 


\section{Scope of Work}

The following is the scope of work as defined in the FEMA/USGS Statement of Work:

Task 1: Collect data from a variety of sources including community surveys, other Federal and State Agencies, National Flood Insurance Program (NFIP) State Coordinators, Community Assistance Visits (CAVs) and FEMA archives. Lists of mapping needs will be obtained from the MNUSS database, community surveys, and CAVs, if available. FEMA archives will be inventoried for effective FIRM panels, FIS reports, and other flood-hazard data or existing study data. Best available base map information, topographic data, flood-hazard data, and hydrologic and hydraulic data will be identified. Data from the Maine Floodplain Management Program database also will be utilized.

Task 2: Contact communities in Somerset County to notify them that FEMA and the State have selected them for a map update, and that a project scope will be developed with their input. Topics to be reviewed with the communities include (1) Purpose of the Flood Map Project (for example, the update needs that have prompted the map update); (2) The community's mapping needs; (3) The community's available mapping, hydrologic, hydraulic, and flooding information; (4) target schedule for completing the project; and (5) The community's engineering, planning, and geographic information system (GIS) capabilities.

On the basis of the collected information from Task 1 and community contacts/meetings in Task 2, the USGS will develop a Draft Project Scope for the identified mapping needs of the communities in Somerset County. The following items will be addressed in the Draft Project Scope: review of available information, determine if and how effective FIS data can be used in new project, and identify other data needed to complete the Project and its source. The Draft Project Scope will establish priority levels for flooding sources to be analyzed and mapped, and estimate schedules and associated costs for completion of the components of flood mapping.

The following subject areas are documented in this report as set forth in the statement of work: available flood-mapping-related data and documented mapping needs, community meetings and contacts, scope and prioritization of mapping needs, and project methods. Scoping-level time and costs for identified mapping needs will be provided as a document separate from this report. The appendix section of this report provides a community by community summary of information obtained and used in the scoping process for all 30 communities in Somerset County that have Flood Hazard Boundary Maps, Flood Insurance Rate Maps (FIRMs), and (or) Flood Insurance Studies (FISs) (table 1). 
Table 1. Organized communities and unorganized territories in Somerset County, Maine. [CID, Community identification number; NSFA, No Specific Flood Hazard Area; FIRM, Flood Insurance Rate Map; -, no data; *, Community has a published Flood Insurance Study]

\begin{tabular}{|c|c|c|c|}
\hline Community & CID & $\begin{array}{l}\text { Population } \\
\text { (year 2000) }\end{array}$ & FIRM date \\
\hline Alder Brook TWP, T03 R03 NB & 230713 & - & NSFA \\
\hline Anson, Town of & 230123 & 2,583 & $7 / 3 / 1995^{*}$ \\
\hline Appleton TWP, T6 R7 BKP WKR & 230714 & - & NSFA \\
\hline Athens, Town of & 230354 & 847 & $9 / 27 / 1985$ \\
\hline Attean TWP, T5 R1 NBKP & 230715 & - & NSFA \\
\hline Bald Mountain TWP, T2 R3 BKP EKR & 230716 & - & NSFA \\
\hline Bald Mountain TWP, T4 R3 NBKP & 230717 & - & NSFA \\
\hline Big Six TWP, T6 R19 WELS & 230545 & - & NSFA \\
\hline Big Ten TWP, T10 R17 WELS & 230719 & - & NSFA \\
\hline Big W TWP & 230546 & - & NSFA \\
\hline Bigelow TWP, T4 R3 BKP WKR & 230718 & - & NSFA \\
\hline Bingham, Town of & 230124 & 989 & $9 / 27 / 1985$ \\
\hline Blake Gore TWP, T5 R4 NBKP & 230720 & - & NSFA \\
\hline Bowtown TWP, T1 R4 BKP WKR & 230721 & - & NSFA \\
\hline Bradstreet TWP, T4 R7 BKP WKR & 230722 & - & NSFA \\
\hline Brassua TWP, T2 R2 NBKP & 230723 & - & NSFA \\
\hline Brighton PLT & 230538 & 86 & NSFA \\
\hline Cambridge, Town of & 230355 & 492 & $9 / 27 / 1985$ \\
\hline Canaan, Town of & 230356 & 2,017 & $9 / 27 / 1985$ \\
\hline Caratunk, Town of & 230539 & 108 & $11 / 1 / 1985$ \\
\hline Carrying Place TWP, T01 R03 BKP WKR & 230753 & - & NSFA \\
\hline Carrying Place TWP, T02 R03 BKP WKR & 230724 & - & NSFA \\
\hline Chase Stream TWP, T1 R6 BKP WKR & 230547 & - & NSFA \\
\hline Comstock TWP, T04 R18 WELS & 230725 & - & NSFA \\
\hline Concord TWP & 230466 & - & $2 / 1 / 1985$ \\
\hline Cornville, Town of & 230358 & 1,208 & $9 / 27 / 1985$ \\
\hline Dead River TWP, T03 R03 BKP WKR & 230726 & - & NSFA \\
\hline Dennistown PLT & 230540 & - & NSFA \\
\hline Detroit, Town of & 230357 & 816 & $8 / 19 / 1985$ \\
\hline Dole Brook TWP, T03 R05 NBKP & 230727 & - & NSFA \\
\hline East Moxie TWP, T02 R04 BKPEKR & 230548 & - & NSFA \\
\hline Elm Stream TWP, T04 R16 WELS & 230728 & - & NSFA \\
\hline Embden, Town of & 230359 & 881 & 9/4/1985 \\
\hline
\end{tabular}




\begin{tabular}{|c|c|c|c|}
\hline Fairfield, Town of & 230125 & 6,573 & $2 / 17 / 1988^{*}$ \\
\hline Flagstaff TWP, T04 R04 BKP WKR & 230729 & - & NSFA \\
\hline Forsyth TWP, T06 R02 NBKP & 230730 & - & NSFA \\
\hline Hammond TWP, T03 R04 NBKP & 230731 & - & NSFA \\
\hline Harmony, Town of & 230360 & 954 & $9 / 27 / 1985$ \\
\hline Hartland, Town of & 230361 & 1,816 & $1 / 1 / 1991$ \\
\hline Highland PLT & 230541 & - & NSFA \\
\hline Hobbstown TWP T04 R06 BKP WKR & 230732 & - & NSFA \\
\hline Holeb TWP, T06 R01 NBKP & 230733 & - & NSFA \\
\hline Indian Stream TWP, T1 R6 BKP EKR & 230549 & - & NSFA \\
\hline Jackman, Town of & 230362 & 718 & 9/4/1985 \\
\hline Johnson Mountain TWP, T2 R6 BKP WKR & 230550 & - & NSFA \\
\hline King \& Bartlett TWP, T04 R05 BKP WKR & 230734 & - & NSFA \\
\hline Lexington TWP, T2 R1 BKP WKR & 230551 & - & NSFA \\
\hline Little W TWP & 230735 & - & NSFA \\
\hline Long Pond TWP, T3 R1 NBKP & 230552 & - & NSFA \\
\hline Lower Enchanted TWP, T02 R05 BKP WKR & 230736 & - & NSFA \\
\hline Madison, Town of & 230126 & 4,523 & $7 / 3 / 1995^{*}$ \\
\hline Mayfield TWP, T02 R02 BKP EKR & 230737 & - & NSFA \\
\hline Mercer, Town of & 230176 & 647 & $5 / 2 / 1994 *$ \\
\hline Misery Gore TWP & 230553 & - & NSFA \\
\hline Misery TWP, T02 R07 BKP WKR & 230738 & - & NSFA \\
\hline Moose River, Town of & 230363 & 219 & $1 / 17 / 1975$ \\
\hline Moscow, Town of & 230364 & 577 & $11 / 1 / 1985$ \\
\hline Moxie Gore TWP, T1 R5 BKP EKR & 230567 & - & NSFA \\
\hline New Portland, Town of & 230365 & 785 & $8 / 19 / 1985$ \\
\hline Norridgewock, Town of & 230178 & 3,294 & $5 / 6 / 1996^{*}$ \\
\hline Palmyra, Town of & 230366 & 1,953 & $8 / 19 / 1985$ \\
\hline Parlin Pond TWP, T3 R7 BKP WKR & 230554 & - & NSFA \\
\hline Pierce Pond TWP, T02 R04 BKP WKR & 230739 & - & NSFA \\
\hline Pittsfield, Town of & 230127 & 4,214 & $1 / 19 / 1996 *$ \\
\hline Pittston Academy Grant TWP, T2 R4 NBKP & 230555 & - & NSFA \\
\hline Pleasant Ridge PLT & 230367 & 83 & $11 / 1 / 1985$ \\
\hline Plymouth TWP, T01 R04 NBKP & 230740 & - & NSFA \\
\hline Prentiss TWP, T04 R04 NBKP & 230741 & - & NSFA \\
\hline Ripley, Town of & 230368 & 452 & $9 / 27 / 1985$ \\
\hline Rockwood Strip TWP, T01 R01 NBKP & 230467 & 390 & $12 / 1 / 1987$ \\
\hline
\end{tabular}




\begin{tabular}{|c|c|c|c|}
\hline Rockwood Strip TWP, T02 R01 NBKP & 230634 & - & NSFA \\
\hline Russell Pond TWP, T05 R16 WELS & 230742 & - & NSFA \\
\hline Sandbar Tract TWP & 230744 & - & NSFA \\
\hline Sandwich Academy TWP, T02 R01 NBKP & 230745 & - & NSFA \\
\hline Sandy Bay TWP, T05 R03 NBKP & 230746 & - & NSFA \\
\hline Sapling TWP, T1 R7 BKP WKR & 230556 & - & NSFA \\
\hline Seboomook TWP & 230747 & - & NSFA \\
\hline Skowhegan, Town of & 230128 & 8,824 & $9 / 20 / 1995 *$ \\
\hline Smithfield, Town of & 230370 & 930 & $9 / 4 / 1985$ \\
\hline Soldiertown TWP, T02 R03 NBKP & 230748 & - & NSFA \\
\hline Solon, Town of & 230371 & 940 & $8 / 19 / 1985$ \\
\hline Squaretown TWP, T2 R5 BKP EKR & 230557 & - & NSFA \\
\hline St. Albans, Town of & 230369 & 1,836 & $9 / 27 / 1985$ \\
\hline St. John TWP, T06 R16 WELS & 230743 & - & NSFA \\
\hline Starks, Town of & 230372 & 578 & $5 / 20 / 1996^{*}$ \\
\hline T03 R04 BKP WKR & 230559 & - & NSFA \\
\hline T03 R05 BKP WKR & 230754 & - & NSFA \\
\hline T04 R05 NBKP & 230755 & - & NSFA \\
\hline T04 R17 WELS & 230756 & - & NSFA \\
\hline T05 R06 BKP WKR & 230757 & - & NSFA \\
\hline T05 R07 BKP WKR & 230758 & - & NSFA \\
\hline T05 R17 WELS & 230759 & - & NSFA \\
\hline T05 R18 WELS & 230560 & - & NSFA \\
\hline T05 R19 WELS & 230561 & - & NSFA \\
\hline T05 R20 WELS & 230562 & - & NSFA \\
\hline T06 R17 WELS & 230760 & - & NSFA \\
\hline T06 R18 WELS & 230563 & - & NSFA \\
\hline T07 R16 WELS & 230761 & - & NSFA \\
\hline T07 R17 WELS & 230564 & - & NSFA \\
\hline T07 R18 WELS & 230762 & - & NSFA \\
\hline T07 R19 WELS & 230763 & - & NSFA \\
\hline T08 R16 WELS & 230764 & - & NSFA \\
\hline T08 R17 WELS & 230874 & - & NSFA \\
\hline T08 R18 WELS & 230565 & - & NSFA \\
\hline T08 R19 WELS & 230566 & - & NSFA \\
\hline T09 R16 WELS & 230875 & - & NSFA \\
\hline T09 R17 WELS & 230876 & - & NSFA \\
\hline
\end{tabular}




\begin{tabular}{llll} 
T09 R18 WELS & 230877 & - & NSFA \\
T10 R16 WELS & 230878 & - & NSFA \\
$\begin{array}{l}\text { Taunton \& Raynham Academy Grant TWP, T1 R1 } \\
\text { NBKP }\end{array}$ & 230544 & - & NSFA \\
Ten Thousand Acre Tract TWP, T1 R6 BKP & 230749 & - & NSFA \\
WKR, TWP & 230542 & - & NSFA \\
The Forks PLT & 230750 & - & NSFA \\
Thorndike TWP, T03 R02 NBKP & 230558 & - & NSFA \\
Tomhegan TWP, T01 R02 NBKP & 230751 & - & NSFA \\
Upper Enchanted TWP, T3 R6 BKP WKR & 230543 & - & NSFA \\
West Forks PLT & 230752 & - & NSFA \\
West Middlesex Canal Grant TWP, T1 R3 NBKP & TOTAL & 50,333 & \\
\hline
\end{tabular}

\section{Description of Somerset County}

Somerset County, centrally located in the State of Maine (fig. 1, 2), encompasses an area of 3,926 square miles $\left(\mathrm{mi}^{2}\right.$ ) and comprises 27 municipalities (26 towns and 1 plantation) and 89 unorganized townships and plantations (table 1, fig. 1,2). The southern end of the county is only one hour from Portland, the State's largest city. The northern end of the county is only one and a half hours from the city of Quebec. The total population in Somerset County reported by the 2000 census was approximately 50,890 people. The population for the 2000 census represents a 2-percent increase over the population reported in the 1990 census (49,400 people) and a 13-percent increase over the population reported in the 1980 census (44,500 people) (University of Maine, 2004; U.S. Census Bureau, 2002). The four largest communities in Somerset County have populations that vary from just under 9000 to just over 4000 .

There are approximately 952 ponds and lakes in Somerset County ranging in surface area from 0.08 acres (Unnamed Pond, in Chase Stream Township) to 75,470 acres (118 $\mathrm{mi}^{2}$ ) (Moosehead Lake) (Maine Office of Geographic Information Systems written commun., November 2005). Moosehead Lake, the largest lake in Maine, is not in Somerset County proper but composes the boundaries of Little W, Big W, Seboomook, Tomhegan, and Sapling Townships, Misery Gore, Rockwood Strip, and Taunton and Raynham Academy Grant. Total surface area of lakes and ponds in Somerset county is approximately 105,000 acres $\left(165 \mathrm{mi}^{2}\right.$ ) (this figure does not include the surface area of Moosehead Lake). The median pond size is 4.6 acres. There are approximately 3,290 mi of rivers and streams in Somerset County (fig 3, 4).

Three major highways pass through Somerset County. U.S. route 201, which runs north-south, U.S. Route 2, which runs east-west, and Interstate 95 in the south-eastern corner. Somerset County's economy includes natural resource based companies such as paper manufacturers and sawmills and boasts being one of the top maple syrup producing counties in the United States. Somerset County is also home to leading edge businesses that manufacture electronic components and there is a new BioTech park. Somerset County is the gateway to the mountains, lakes, rivers and forests of western Maine. Maine's four seasons offer opportunities to experience skiing, fishing, white water rafting, hiking, snowmobiling and many other recreational activities (Maine Floodplain Management Program, State Planning Office, written commun. March 22, 2006). 


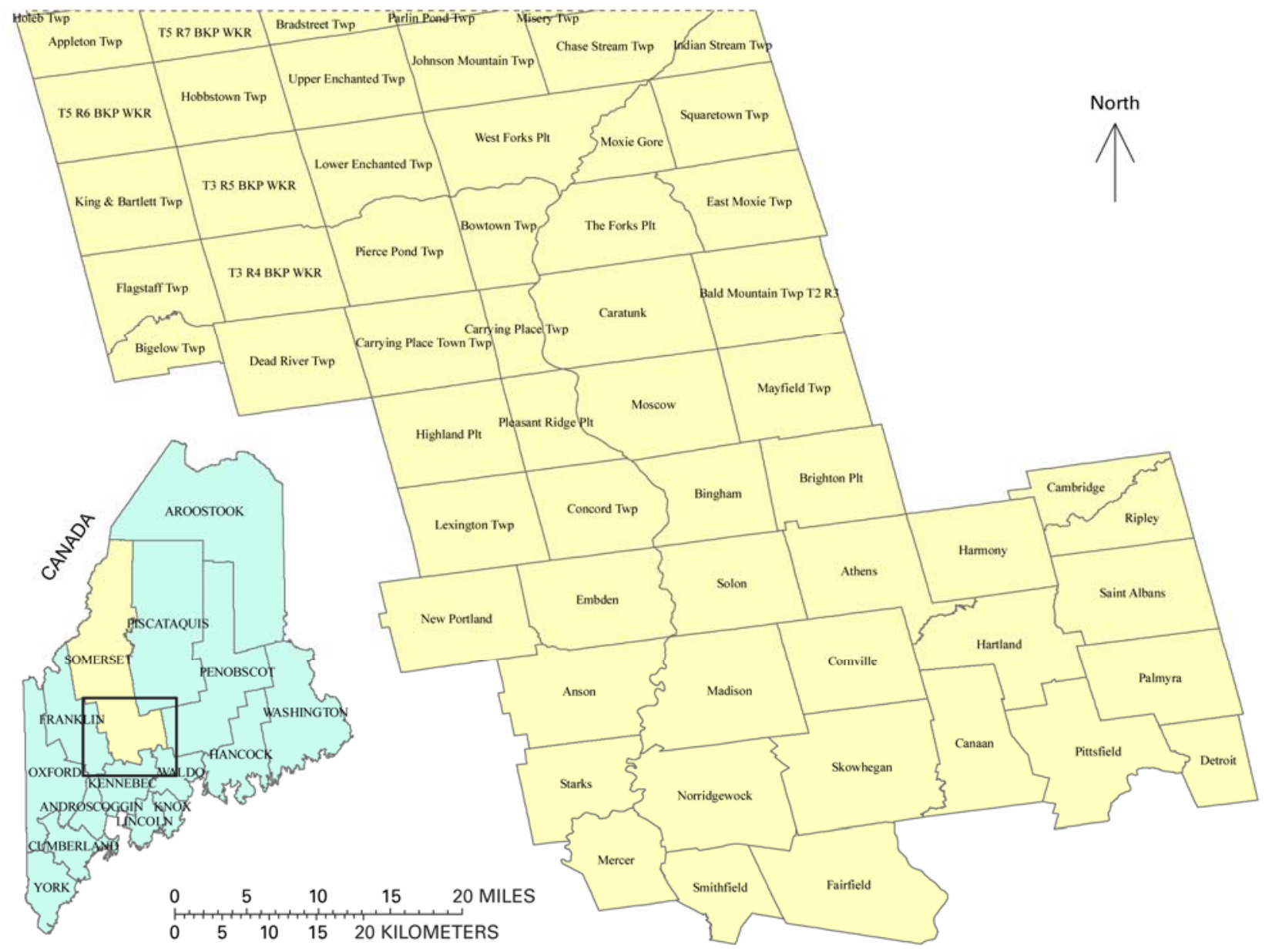

Figure 1. Communities and unorganized territories in (southern) Somerset County, Maine. 


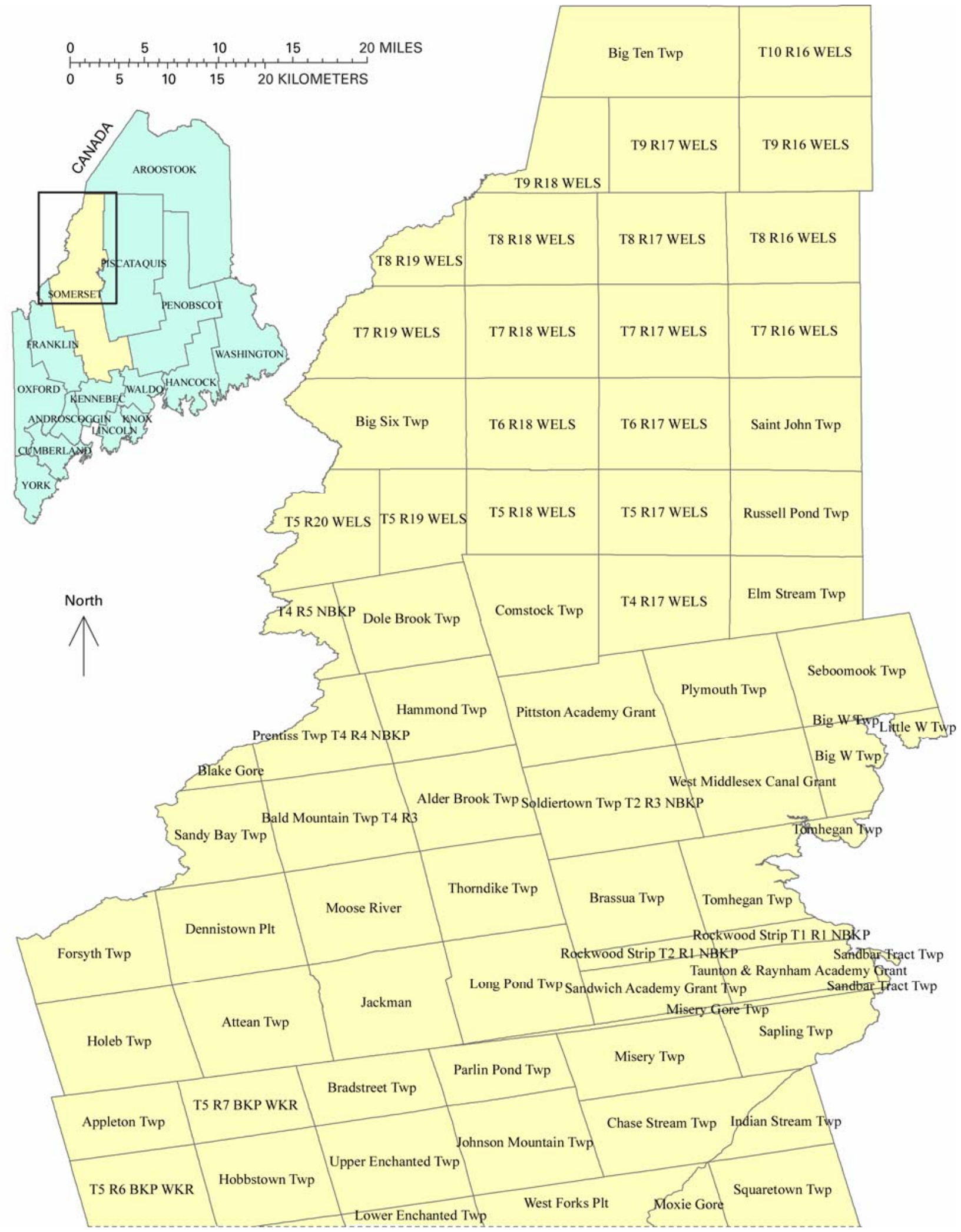

Figure 2. Communities and unorganized territories in (northern) Somerset County, Maine. 


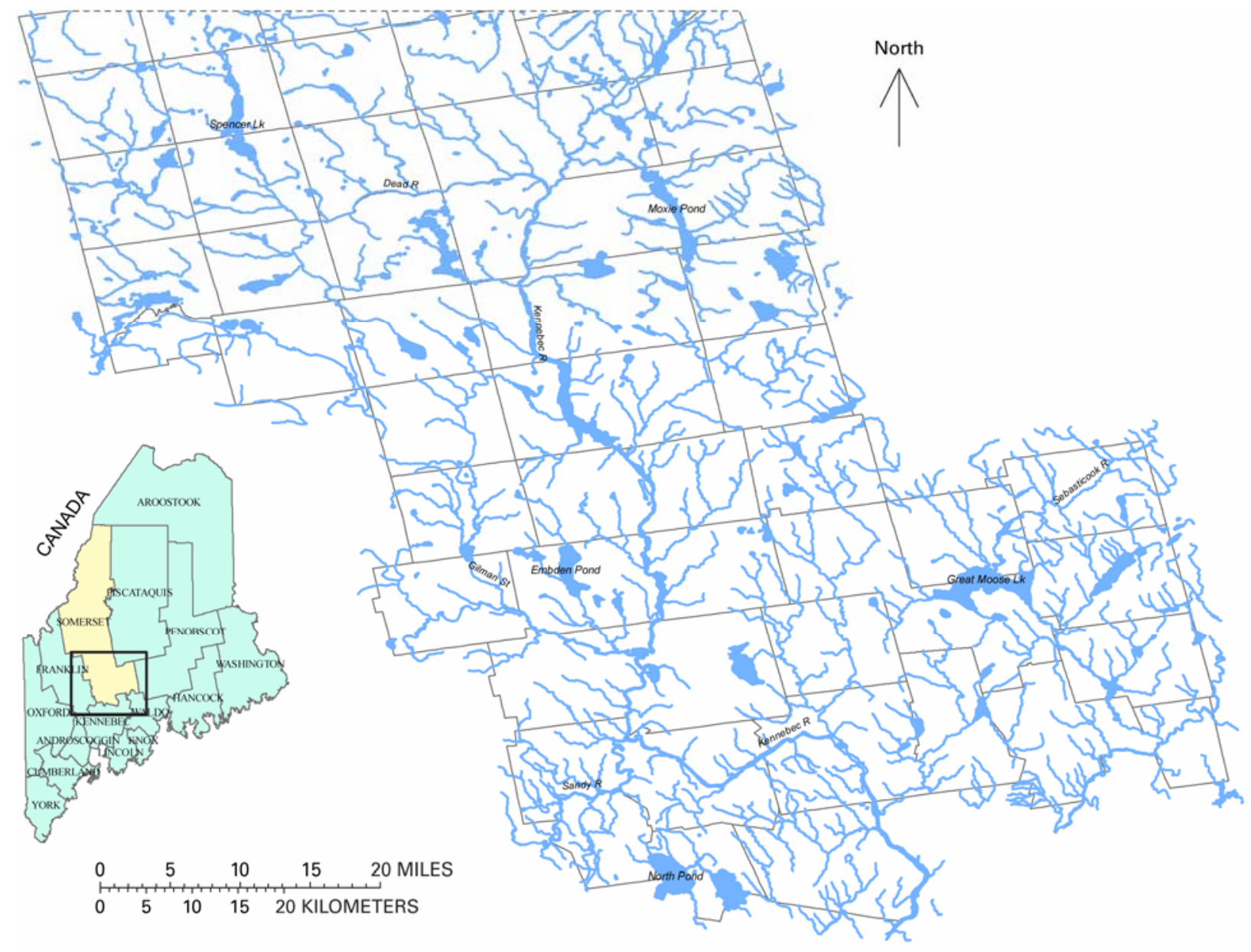

Figure 3. Hydrology of (southern) Somerset County, Maine. 


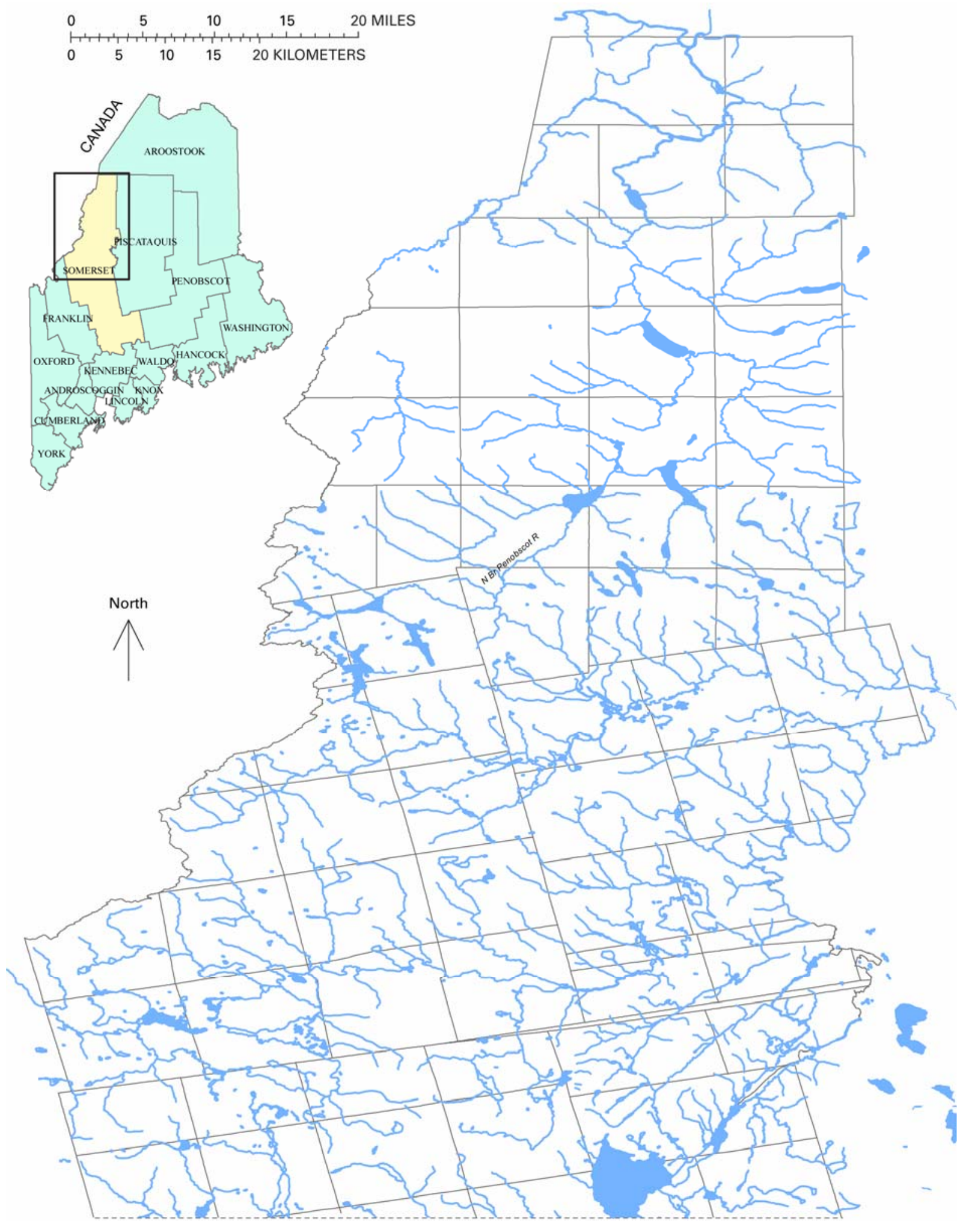

Figure 4. Hydrology of (northern) Somerset County, Maine. 


\section{Section 2. Available Flood-Mapping Data and Mapping Needs}

Flood-mapping data and mapping needs available prior to community scoping meetings were identified in pre-scoping efforts as part of National Services Provider (NSP) Task Order Number 4 (Burm, 2005). For the scoping activities documented in this report, the USGS reviewed the prescoping report to ensure the data contained in this report is utilized to the maximum extent possible and to avoid duplication of effort.

\section{Community FISs and FIRMs}

There are 8 communities that have FIRMs with active FIS reports in Somerset county and 22 communities with FIRMs with only unnumbered A-zones; the remainder of the communities are designated as having no specific flood hazard areas (NSFHA) (table 1; Burm, 2005). There are 82 riverine flood profiles for Somerset County. Communities with FIS reports, with A-zone FIRMS, and communities with unmapped NSFHAs are itemized and flood profiles are summarized by community in the March 2005 Pre-scoping Report for Somerset County (Burm, 2005).

The effective map dates range from 1975 in the Town of Moose River to 2000 in the Town of Starks. Approximately two-thirds of the FIRMs in Somerset County are 20 years old or older; 93 percent are 10 years or older. The oldest FIRM is 31 years old, the most recent is 6 years old, and the average age is approximately 18 years. It is important to note that the effective map date is the date the map was last revised. Some revisions were minor adjustments and did not affect entire map panels. As a result, much of the information depicted on the county's floodplain maps is likely to be older than 18 years.

\section{State of Maine Best Available Data (BAD) for Unnumbered A-Zones}

The Maine Floodplain Management Program has developed, over several years, a data set that tabulates information about the best available data (base flood elevations) for water bodies designated as unnumbered "A" zones on flood maps for communities throughout the State. The base flood elevations tabulated in this data set are derived from hydrologic and (or) hydraulic studies of water bodies that may be published in FISs for adjacent communities or published as part of flood studies not directly related to FEMA FISs (e.g. Army Corps of Engineer projects, Natural Resources Conservation Service projects, and Letter of Map Changes). These data are used in this report as part of the prioritization of mapping needs for a community (see section: Scope and Prioritization of Mapping Needs in Somerset County). The existence of these data was documented in the March 2005 Pre-scoping Report for Somerset County (Burm, 2005) and are documented in the appendix of this report on a community-by-community basis. Information about these data is available from the Maine Floodplain Management Program web site at: http://www.state.me.us/spo/flood/bad/

\section{Letters of Map Change (LOMCs)}

A Letter of Map Change (LOMC) is a letter issued by FEMA in response to a request to revise or amend an effective National Flood Insurance Program (NFIP) map to remove a property or reflect changed flooding conditions on the effective map. LOMCs may include Letters of Amendments (LOMAs), Letters of Map Revisions (LOMRs), and Letter of Map Revision based on Fill (LOMR-F) as defined below: 
- LOMAs: A LOMA is an official amendment, by letter, to an effective NFIP map. A LOMA establishes the property location in relation to the Special Flood Hazard Area (SFHA). There is no appeal period for LOMAs, and the letter becomes effective the date that it is sent.

- LOMRs: A LOMR is an official revision, by letter, to an effective NFIP map. A LOMR may change flood-insurance risk zones, floodplain and (or) floodway boundary delineations, planimetric features, and (or) Base Flood Elevations (BFEs). The effective date of a LOMR depends on the type of change requested. For example, some LOMR's are effective on the date that the letter is issued and others become effective following an appeal period (typically 30 to 90 days or 6 months).

- LOMR-F: A Letter of Map Revision based on Fill (LOMR-F) may be filed as a special case of the LOMR. A LOMR-F provides FEMA's determination concerning whether a structure or parcel has been elevated on fill above the BFE and excluded from the SFHA. A LOMR-F is an official revision, by letter, to an effective NFIP map. The letter becomes effective on the date that it is sent.

In addition to the categories above, conditional LOMAs, LOMRs, and LOMR-Fs may be issued by FEMA to comment on a proposed project. The letter does not revise an effective NFIP map, but indicates whether the project, if built as proposed, would be recognized by FEMA.

\section{LOMCs in Somerset County}

The presence and number of LOMCs in a community can be an indication of increasing development in a community and (or) problematic flood hazard boundaries. LOMCs are used in this report as part of the prioritization of mapping needs for a community (see section: Scope and Prioritization of Mapping Needs in Somerset County). The March 2005 Prescoping Report for Somerset County (Burm, 2005) tabulates LOMC data for the county. A Geographic Information System (GIS) digital data set representing georeferenced locations of LOMCs within Somerset County was created as part of the pre-scoping effort.

\section{Community Flood Ordinances}

The Maine Floodplain Management Program provides all participating communities (92 percent of the State's communities) with model floodplain management ordinances, guidance and review, and maintains all community flood ordinances on file. As documented in the March 2005 Prescoping Report for Somerset County (Burm, 2005), the contact for community flood ordinances is the Maine Floodplain Management Program:

Brigitte Ndikum-Nyada

Planning and Research Associate

Maine Floodplain Management Program

State Planning Office

184 State Street, 38 SHS

Augusta, ME 04333

Tel: 207-287-8932

Fax: 207-287-6489 


\section{Mapping Needs Update Support System (MNUSS)}

In accordance with section 575 of the National Flood Insurance Reform Act of 1994, FEMA assesses "...the need to revise and update all floodplain areas and flood risk zones identified, delineated, or established based on an analysis of all natural hazards affecting flood risks." FEMA initiated the Mapping Needs Assessment (MNA) process, which identifies and prioritizes flood hazard mapping needs for communities nationwide. As part of this effort, FEMA developed the Mapping Needs Update Support System (MNUSS), which is an interactive, web-based software application that maintains an inventory of needs for future map updates. In particular, MNUSS stores information on the following two types of update needs:

- Map Maintenance Needs: Includes changes to base map information, such as the addition of new roads, changes to corporate limits, and incorporation of LOMCs.

- Flood Data Update Needs: Includes changes to flood hazard areas as a result of changes in hydrologic and hydraulic conditions, changes to Base Flood Elevations (BFEs), and (or) changes in the floodplain delineation.

Mapping needs may be viewed and entered into MNUSS by a variety of parties, including FEMA Headquarters and Regional offices, state NFIP coordinators, study contractors, Cooperating Technical Partners (CTPs), and other Federal agencies, such as the U.S. Army Corps of Engineers (USACE) and the USGS. All new or edit needs are reviewed and approved by the FEMA MNUSS controller prior to entry into the system.

The March 2005 Pre-scoping Report for Somerset County (Burm, 2005) tabulates MNUSS entries for the county. As part of the scoping process, existing entries in MNUSS were retrieved by USGS and reviewed with the State Planning Office Floodplain Management Program and community representatives. The review process resulted in the identification of duplicate, outdated, missing, and (or) erroneous entries. These findings will provide the basis for updates to MNUSS or its successor upon completion of the scoping report. Existing MNUSS entries are compiled in appendix D.

\section{Community Assistance Visits (CAVs) and Community Assessment Contacts (CACs)}

CAVs and CACs provide assistance to communities regarding the administration and enforcement of their floodplain management ordinances. CAV and CAC data for the county are tabulated in the March 2005 Pre-scoping Report for Somerset County (Burm, 2005) and are listed in the appendix of this report (Appendix A).

\section{GIS Data}

Most GIS data in Maine reside with the Maine Office of GIS (MEGIS) as the agency acts as a central repository for these data. Although not every community shares their GIS data with MEGIS, many data sets are shared and served over the Internet. Data can be accessed on the MEGIS web site at: http://apollo.ogis.state.me.us/. Community-specific data that is not shared with MEGIS are documented as part of the community scoping-meeting process (see interview data in Appendix). All data served by MEGIS are referenced to North American Datum 1983 (NAD83), Universal Transverse Mercator (UTM) Zone 19, in meters, and are available to FEMA. 


\section{Base Map Data}

Base map layers maintained by MEGIS include features such as roads, streams, and political boundaries. Base map data layers have been acquired from a variety of sources including the USGS data and represent many of the feature types found on USGS topographic maps. More recently developed data were derived from various sources providing improved base map accuracy. Existing coverages maintained by MEGIS can be linked to or viewed at the following URL:

http://apollo.ogis.state.me.us/

Only the most northern quarter of Somerset County has no digital orthophotography available (fig. 5). The most detailed orthophotography (2-foot resolution) is in the southern half (most populated part) of Somerset county; the 2-foot (each image pixel representing a planimetric square 2 feet on a side) imagery data set is a true-color mosaic of high-resolution digital orthophotographs produced from aerial photos collected over areas of southwest Maine in 2003 and 2004 (fig. 5).

The remaining quarter of the county has black and white USGS digital orthophoto quarter quadrangle (USGS DOQQ, 1:12,000; 1998, 1992) data available as documented in the March 2005 Pre-scoping Report for Somerset County (Burm, 2005). The DOQQs are FEMA's default standard for the base map. The accuracy and quality of the DOQQs meets National Map Accuracy Standards at 1:12,000 scale for 3.75-minute quarter quadrangles, plus or minus 33.33 feet or 10 meters.

Community-specific aerial photography is documented as part of the community scopingmeeting process (see Appendix). The town of Fairfield indicated they had aerial photography shot in 1990 in hard-copy format only - scale unknown. The town of Norridgewock has had aerial photography done, though date, scale, and format are unknown. The town of Jackman does not have their own aerial photography data, but indicated that they have local people that can do aerial photography and that the town may consider cost sharing if necessary. The town of Solon has color aerial photography shot in 1999. The town of Skowhegan indicated they have aerial photography over various dates, though dates, scale, and format are unknown. 


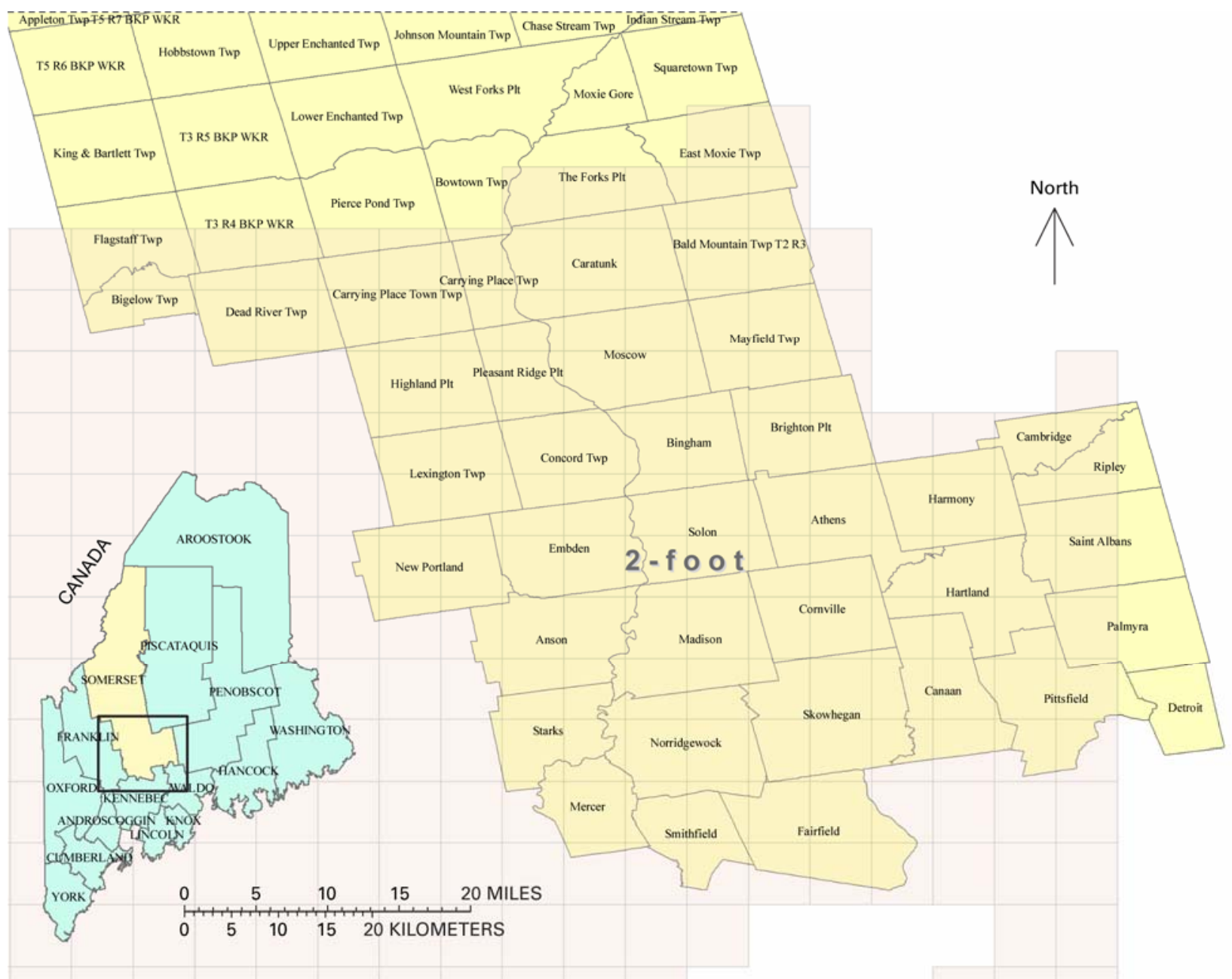

Figure 5. Orthophotography index for Somerset County, Maine. Index grid shows coverage of 2-foot (each image pixel representing a planimetric square 2 foot on a side) orthophotography archived and served through the internet by the Maine Office of Geographic Information Systems (MEGIS).

\section{Topographic Data}

Digitally scanned USGS 7.5-minute quadrangles provide topographic data for the entire state of Maine with 10- and 20-ft contour intervals, variable by location. Digital Elevation Models (DEM) also are available through the USGS National Elevation Dataset (NED). The NED has been developed by merging the highest-resolution, best quality elevation data available across the United States into a seamless raster format. NED horizontal datum for Maine is NAD83 and vertical datum is North American Vertical Datum 1988 (NAVD88). The NED is continually updated as best available DEM data become available. DEM data with 30 meter $(\mathrm{m})$ resolution (each raster pixel represents a planimetric square 30 meters on a side) are available for the entire state of Maine. DEM data with 10$m$ resolution (1/3 arc second) are available for the entire state of Maine except for extreme northern Somerset and Oxford Counties. DEM data can be downloaded through the USGS Seamless Data Distribution Web site at http://seamless.usgs.gov/web site/seamless/viewer.ph.

The Maine Department of Transportation (MDOT) routinely collects detailed topographic data for highway projects. The data are typically limited to an area within $300 \mathrm{ft}$ of the centerline of the 
highway. The scope, scale, and accuracy of the data are project specific and depend on the flight level of the survey. MDOT does not maintain any kind of searchable database cataloging these data. The MDOT Survey and Photogrammetric Group is willing to search their files for available data if they are provided a GIS shapefile of an area of interest. As of this draft, MDOT has been provided GIS shapefiles of scoped study areas for Somerset County. Availability of data is pending. The primary contact for topographic data from the MDOT Survey and Photogrammetric Group is Tim Liseige, Photogrammetric and Control Engineer, (207) 624-3493, tim.liseige@maine.gov.

Community-specific topographic data are documented as part of the community scopingmeeting process (see Appendix). The town of Jackman indicated that they have limited contour data on Wood Pond collected in support of a sewer project in 1984. The planning board representative for the town of Solon thinks that their 1999 color photography may be useable for deriving topography data but suspects there may be too many leaves on the trees at the time the photographs were shot. The town of Skowhegan indicated that 3-foot contour data for the downtown area are available upon request through the Maine Department of Transportation (MDOT).

\section{Hydrography Data}

MEGIS, in cooperation with the USGS, is currently enhancing Maine's 1:24,000 digital hydrography data to create National Hydrography Dataset (NHD) high-resolution data (spatial data describing hydrologic features). The NHD data are partitioned into the following layers: streams, ponds, rivers, coast, and National Wetlands Inventory (NWI) data. Progress in this effort is ongoingthe current status of these data can be determined by contacting MEGIS at (207) 624-8800 or by visiting their web site http://apollo.ogis.state.me.us/. NHD data are available for download from the NHD geodatabase at http://nhdgeo.usgs.gov/viewer.htm.

Community-specific hydrography data are documented as part of the community scopingmeeting process (see Appendix). Only the town of Skowhegan indicated that they had communityspecific hydrography data. The town of Skowhegan indicated they have a limited hydrologic/hydraulic study at the site of the New Balance warehouse.

\section{Community GIS Contact Information}

The March 2005 Pre-scoping Report for Somerset County (Burm, 2005) documented the GIS capabilities of communities in Somerset County. Additional GIS contact information obtained through community scoping meetings is provided in the Appendix on a community by community basis as part of the interview data.

\section{Community Meetings and Contacts}

One community scoping meeting was held for Somerset County at the Skowhegan Community Center, on Thursday, November 3rd, from 6 to 8 p.m. An invitation letter (with agenda) specifying the time and place and purpose of the meeting was mailed to at least two community officials in every municipality. The letters were addressed to the community code enforcement officer and to the community manager or first selectperson. Planners and surveyors were invited if they were known to the Maine Floodplain Management Program to be involved in floodplain management for their community. Letters were mailed to the Land Use Regulatory Commission (LURC) which provides land use and other governmental functions for the unorganized territories and townships, and to regional planning commissions, and the county emergency management agency (EMA) director. Example copies of the letter and meeting agenda are attached to this report.

The goals of these meetings were to 
- Inform the communities of the nature and the intent of the flood map update process, and

- Solicit community input and discuss the flood-prone areas that communities would like to include as a part of the flood map update.

Robert Dudley, USGS Maine Water Science Center, Bonnie Cowle, Maine Floodplain Management Program, and Stuart Rooney, Watershed Concepts representing FEMA, conducted the meeting. Community representatives were provided an overview of the Map Modernization Program and the map production schedule and technical process.

The latter part of the meeting involved breaking out into small groups with group leaders from USGS, Maine Floodplain Management Program, and Watershed Concepts. The group leaders administered and assisted with the completion of map needs interview forms (example attached, Appendix E). Community representatives were provided copies of their community's flood maps and were encouraged to mark them up as necessary. These marked-up flood maps reside with the Maine Floodplain Management Program. Community representatives were asked to explain and prioritize their needs if possible.

MNUSS entries were reviewed with community representatives for verification. The following two common issues were identified: (1) most MNUSS entries address needs which would be fulfilled with improved base maps such as street locations, street names, and overall difficulty using the map due to lack of distinguishing ground features; and (2) the field indicating "anticipated BFE change" was commonly confused with how much the community thought the BFE was in error - for example, the field may indicate "Increased By 1 to 5 feet" but the need notes may indicate a hydraulic structure change that would result in a lower BFE, so in this case the "anticipated BFE change" field is populated with a value of how much the community thinks the BFE is in error rather than how much the BFE is expected to change should the reach be restudied.

During the scoping meetings, the Maine Floodplain Management Program's Best Available Data (BAD) were reviewed with each community representative if BAD data existed for that community. The review was done to make the community aware of the information if they were not already aware of it, and to solicit input on BAD data if any additional information was available to the community that was not listed in the State Planning Office's (SPO) BAD database.

The following three subject areas encompass the data gathered from the scoping meeting process and completion of interview forms: (1) community contact information, (2) areas of the existing flood maps where there are significant problems (poor mapping or development pressures) or changes to hydrologic/hydraulic conditions, and (3) community mapping resources. Communities that did not attend the meetings were sent interview forms, MNUSS entries, and BAD data and asked to review, complete, and return them. The data from the scoping meetings were entered into the watershed information system (WISE) scoping application and are reported for each community in the Appendix as part of the interview data (Appendix B, C, and D).

\section{Scope and Prioritization of Mapping Needs in Somerset County}

USGS staff (Robert Dudley, Charles Schalk) met with Maine Floodplain Management Program staff (Lou Sidell, Bonnie Cowle) in September 2005 as an initial kick-off meeting for the scoping process. An action item resulting from that meeting involved Maine Floodplain Management Program staff arriving at a list of factors that should be considered for prioritizing potential mapping needs in the county. Table 2 lists the factors and their qualitative weight, as determined by Maine Floodplain Management Program staff, to be considered for prioritization of flood mapping needs in the county. 
Table 2. Maine Floodplain Management Program factors and qualitative weight for prioritization of community-based flood mapping needs in Somerset County.

[Prioritization factors are listed approximately in order from highest to lowest importance; LOMCs, Letters of map change; MNUSS, Mapping needs update support system]

\begin{tabular}{ll}
\hline \multicolumn{1}{c}{ Community Prioritization Factors } & \multicolumn{1}{c}{ Weight } \\
\hline Map age & Very High \\
Map type & Very High \\
Population & High \\
Population growth & High \\
Number of LOMCs & High \\
Number of insurance policies & High \\
Ratio of insurance policies to claims & Medium \\
Presence of best available data & Medium \\
Number of shoreland zoning permits in the vicinity of the water body & Medium \\
Community-specified map needs that coincide with map needs documented in the & Medium to Low \\
Maine Floodplain Management Database and MNUSS & Medium \\
Repetitive loss & \\
\hline
\end{tabular}

Mapping needs were grouped into one of four different types of studies required to create or update flood hazard zones.

- Baseline-DFIRM only: The most economical method of creating a countywide DFIRM is through digitizing flood-hazard information from the effective FIRMs and FISs onto new mapping. This baseline option is currently being undertaken by MEGIS and other FEMA contractors.

- Redelineation: Existing hydrologic and hydraulic studies of the water body are adequate and the water body requires only the redelineation of the base flood elevations using updated topographic data.

- Limited Detailed Study: Automated tools are used to produce digital information or floodmapping for the water body in question has already been studied in detail and requires limited technical reworking of the hydrologic and (or) hydraulic analysis or the water body in question has not been studied in detail but it is expected that approximate methods would suffice to adequately map the flood hazard.

- Detailed Study: Can be performed to develop the digital information, including field surveyed cross-sections and structures. Because this is the most expensive type of study that FEMA can perform, the scope of the detailed study may be limited.

Note that Detail and Limited Detail studies are also assumed to need redelineation using updated topographic data, incorporating results from the new hydrologic and (or) hydraulic analyses.

USGS staff (Robert Dudley, Charles Schalk) met with Maine Floodplain Management Program staff (Bonnie Cowle) December 5, 2005 to review interview data and marked-up maps and to arrive at an initial list of mapping needs for the county. The map needs derived through this meeting were entered into the WISE scoping application. During this meeting, Maine Floodplain Management 
Program staff provided first-cut prioritization on a scale from 1 to 3 (1=highest) on the basis of community need and historical community involvement in floodplain management.

Other first-cut prioritization factors included BAD, connectivity, and historically documented mapping needs. Higher priority was given to A-zone waterbodies with existing BAD where maps could be created or greatly improved by simply collecting improved topographic information and redelineating existing detailed base flood elevations. Higher priority was given to waterbodies with high connectivity, where connectivity is a measure of the number of neighboring communities that are adjacent to or would otherwise benefit from improved mapping of a particular water body. For example, an A-zone river reach that connected to a detail study upstream or spanned multiple communities or a lake that bordered multiple communities would receive higher priority than a pond contained within the corporate limits of a single community. Higher priority was given to waterbodies that had been historically documented as a mapping need in either the Maine Floodplain Management Program's Database or MNUSS or both. Historical documentation of a mapping need is indicative of an ongoing need that has been known to be a need in the past.

\section{Prioritized Mapping Needs and Scopes}

Mapping needs for the county compiled in consultation with the Maine Floodplain Management Program were ranked on the basis of prioritization scoring factors (table 3). Summing the scoring factors produced a community-based prioritized list of mapping needs involving redelineation, limited detail study, or detail study (table 4, fig. 6).

A second community-based prioritized list was created for map digitization only (table 5, fig. 6). This second list provides a way to prioritize communities that need modernized maps but do not necessarily have map revision needs (redelineation, limited detail study, or detail study). The scoring formula for this prioritized list used the same factors as those used for table 4 except for presence of BAD, historical mapping needs, water body priority, and water body connectivity. 
Table 3. Scoring formula for prioritization of community-based flood mapping needs in Somerset County.

[Min, minimum data value for the variable of interest; Max, maximum data value for the variable of interest; N/A, not applicable; $\mathrm{mi}^{2}$, square miles; BAD, best available data; LOMCs, letters of map change; Maine Floodplain Management map type codes: b, unnumbered A-zones only; c, base- flood elevations without floodway; d, base-flood elevations with floodway; e, coastal]

\begin{tabular}{|c|c|c|c|c|c|}
\hline \multicolumn{2}{|c|}{ Community population1 } & \multicolumn{2}{|c|}{ Presence of BAD } & \multicolumn{2}{|c|}{$\begin{array}{l}\text { Historical mapping need coincides } \\
\text { with community-specified need }\end{array}$} \\
\hline Range & Score & Range & Score & Range & Score \\
\hline \multirow{2}{*}{$\begin{array}{l}\operatorname{Min}=83 \\
\operatorname{Max}=4,214\end{array}$} & \multirow{2}{*}{$\begin{array}{l}1 \text { point per } 500 \\
\text { people; } \\
\text { maximum of } 50 \\
\text { points }\end{array}$} & Yes & 10 points & Yes & 5 points \\
\hline & & No & 0 & No & 0 \\
\hline \multicolumn{2}{|c|}{ Population Density (people/mi2) } & \multicolumn{2}{|c|}{ Number of insurance policies } & \multicolumn{2}{|c|}{ Number of LOMCs } \\
\hline Range & Score & Range & Score & Range & Score \\
\hline $\begin{array}{l}\operatorname{Min}=4 \\
\operatorname{Max}=89\end{array}$ & $\begin{array}{l}1 \text { point per } 10 \\
\text { people/mi } \\
\text { maximum of } 50 \\
\text { points }\end{array}$ & $\begin{array}{l}\operatorname{Min}=0 \\
\operatorname{Max}=27\end{array}$ & $\begin{array}{l}1 \text { point per } \\
\text { policy }\end{array}$ & $\begin{array}{l}\operatorname{Min}=0 \\
\operatorname{Max}=42\end{array}$ & $\begin{array}{l}1 \text { point per } \\
\text { LOMC }\end{array}$ \\
\hline \multicolumn{2}{|c|}{ Population Growth2 (percent) } & \multicolumn{2}{|c|}{ Ratio of claims to policies } & \multicolumn{2}{|c|}{ Number of shoreland zoning permits } \\
\hline Range & Score & Range & Score & Range & Score \\
\hline $\begin{array}{l}\operatorname{Min}=-28 \\
\operatorname{Max}=70\end{array}$ & $\begin{array}{l}1 \text { point per } 5 \\
\text { percent (can be } \\
\text { negative) }\end{array}$ & $\begin{array}{l}\operatorname{Min}=0 \\
\operatorname{Max}=1.2\end{array}$ & $\begin{array}{l}5 \text { points } x \text { the } \\
\text { ratio of claims to } \\
\text { policies }\end{array}$ & $\begin{array}{l}\operatorname{Min}=0 \\
\operatorname{Max}=68\end{array}$ & $\begin{array}{l}0.2 \text { point per } \\
\text { shoreland } \\
\text { zoning permit }\end{array}$ \\
\hline \multicolumn{2}{|c|}{ Map age (years) } & \multicolumn{2}{|c|}{ Number of repetitive loss claims } & \multicolumn{2}{|c|}{ Water body connectivity } \\
\hline Range & Score & Range & Score & Range & Score \\
\hline $\begin{array}{l}\operatorname{Min}=10 \\
\operatorname{Max}=21\end{array}$ & 1 point per year & $\begin{array}{l}\operatorname{Min}=0 \\
\operatorname{Max}=2\end{array}$ & $\begin{array}{l}1 \text { point per } \\
\text { repetitive loss } \\
\text { claim }\end{array}$ & $\begin{array}{l}\operatorname{Min}=1 \\
\operatorname{Max}=16\end{array}$ & $\begin{array}{l}1 \text { point per } \\
\text { connected } \\
\text { community }\end{array}$ \\
\hline \multicolumn{2}{|c|}{ Map type } & \multicolumn{2}{|c|}{ Water body priority } & & \\
\hline Range & Score & Range & Score & & \\
\hline $\mathrm{b}$ & 20 points & 1 (highest) & 10 points & & \\
\hline $\mathrm{c}$ & 10 & 2 & 6 & & \\
\hline $\mathrm{d}$ & 5 & 3 (lowest) & 3 & & \\
\hline $\mathrm{e}$ & 5 & & & & \\
\hline
\end{tabular}

${ }^{1}$ On the basis of the 2000 census.

${ }^{2}$ Population growth computed for the period 1980-2000. 
Table 4. Prioritized community-based flood mapping needs in Somerset County requiring redelineation, limited detail study, or detail study.

\begin{tabular}{|c|c|c|c|c|}
\hline Rank & Water body & Community & Study Type & Score \\
\hline 1 & Indian Pond & St. Albans, Town of & Redelineation & 131.8 \\
\hline 2 & Great Moose Lake & St. Albans, Town of & Redelineation & 124.8 \\
\hline 3 & Indian Stream & St. Albans, Town of & Redelineation & 119.8 \\
\hline 4 & Great Moose Lake & Hartland, Town of & Redelineation & 110.9 \\
\hline 5 & Sibley Pond & Canaan, Town of & Redelineation & 109.3 \\
\hline 6 & Morrill Pond & Hartland, Town of & Redelineation & 104.9 \\
\hline 7 & Mulligan Stream & St. Albans, Town of & Detail Study & 101.8 \\
\hline 8 & Great Moose Lake & Harmony, Town of & Redelineation & 93.2 \\
\hline 9 & Moosehead Lake & Rockwood Strip TWP, T01 R01 NBKP & Redelineation & 90.0 \\
\hline 10 & Sebasticook River & Hartland, Town of & Detail Study & 89.9 \\
\hline 11 & Carrabassett Stream & Canaan, Town of & Detail Study & 88.3 \\
\hline 12 & Sibley Pond & Pittsfield, Town of & Redelineation & 87.6 \\
\hline 13 & North Pond & Smithfield, Town of & Redelineation & 85.9 \\
\hline 14 & Whites Pond & Palmyra, Town of & Redelineation & 83.2 \\
\hline 15 & Carrabassett River & New Portland, Town of & Detail Study & 80.5 \\
\hline 16 & Wood Pond & Jackman, Town of & Redelineation & 74.9 \\
\hline 17 & Kennebec River & Concord TWP & Redelineation & 74.1 \\
\hline 18 & Sebasticook River & Palmyra, Town of & Detail Study & 73.2 \\
\hline 19 & Long Pond & Jackman, Town of & Redelineation & 72.9 \\
\hline 20 & Farnham Brook & Pittsfield, Town of & Detail Study & 70.6 \\
\hline 21 & Sebasticook River & Pittsfield, Town of & Detail Study & 69.6 \\
\hline 22 & Nokomis Pond & Palmyra, Town of & Detail Study & 67.2 \\
\hline 23 & Austin Stream & Moscow, Town of & Redelineation & 66.9 \\
\hline 24 & Ironbound Pond & Solon, Town of & Detail Study & 66.5 \\
\hline 25 & Lemon Stream & New Portland, Town of & Detail Study & 65.5 \\
\hline 26 & Gilman Pond & New Portland, Town of & Detail Study & 63.5 \\
\hline 27 & Higgins Brook & Harmony, Town of & Detail Study & 63.2 \\
\hline 28 & Lake Como & Harmony, Town of & Detail Study & 63.2 \\
\hline 29 & Ripley Pond & Ripley, Town of & Redelineation & 62.6 \\
\hline 30 & Gilman Stream & New Portland, Town of & Detail Study & 62.5 \\
\hline 31 & East Pond & Smithfield, Town of & Detail Study & 60.9 \\
\hline 32 & Fall Brook & Solon, Town of & Detail Study & 59.5 \\
\hline 33 & Barker Pond & Cornville, Town of & Detail Study & 58.5 \\
\hline 34 & West Branch Wesserunsett & Athens, Town of & Detail Study & 56.5 \\
\hline 35 & Brassua Lake & Rockwood Strip TWP, T01 R01 NBKP & Detail Study & 56.0 \\
\hline 36 & Ironbound Pond & Athens, Town of & Detail Study & 53.5 \\
\hline 37 & Wyman Lake & Pleasant Ridge Plt & Detail Study & 49.7 \\
\hline 38 & Moose River & Jackman, Town of & Limited Detail Study & 47.9 \\
\hline
\end{tabular}


Table 5. Prioritized community-based flood mapping need in Somerset County on the basis of nonrevised baseline-DFIRM production only.

\begin{tabular}{llr}
\hline Rank & Community & Score \\
\hline 1 & St. Albans, Town of & 129.8 \\
2 & Fairfield, Town of & 98.8 \\
3 & Skowhegan, Town of & 93.0 \\
4 & Hartland, Town of & 91.8 \\
5 & Canaan, Town of & 79.3 \\
6 & Embden, Town of & 78.1 \\
7 & Norridgewock, Town of & 65.7 \\
8 & Palmyra, Town of & 63.2 \\
9 & Harmony, Town of & 63.2 \\
10 & New Portland, Town of & 59.5 \\
11 & Pittsfield, Town of & 58.6 \\
12 & Anson, Town of & 57.0 \\
13 & Madison, Town of & 55.4 \\
14 & Cornville, Town of & 54.5 \\
15 & Smithfield, Town of & 52.9 \\
16 & Caratunk, Town of & 52.7 \\
17 & Moose River, Town of & 49.5 \\
18 & Detroit, Town of & 49.1 \\
19 & Moscow, Town of & 48.9 \\
20 & Solon, Town of & 48.5 \\
21 & Bingham, Town of & 47.2 \\
22 & Cambridge, Town of & 46.0 \\
23 & Ripley, Town of & 45.6 \\
24 & Athens, Town of & 45.5 \\
25 & Rockwood Strip TwP, T01 R01 NBKP & 44.0 \\
26 & Concord TwP & 43.1 \\
27 & Jackman, Town of & 42.9 \\
28 & Pleasant Ridge PLT & 37.6 \\
29 & Mercer, Town of & 35.2 \\
30 & Starks, Town of & 28.1 \\
\hline & & \\
& &
\end{tabular}




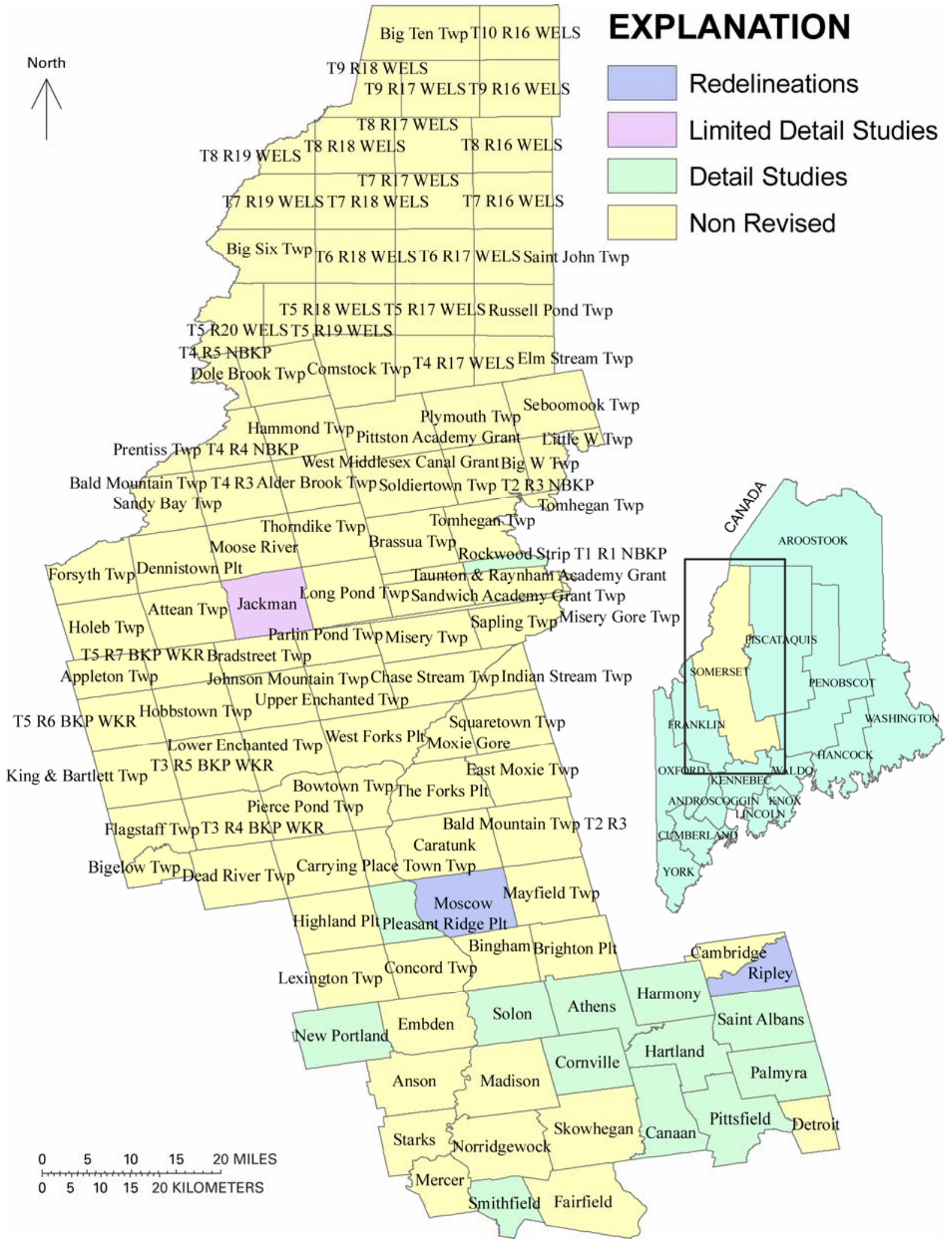

Figure 6. Mapping needs by community in Somerset County. 


\section{Project Time and Costs for Identified Mapping Needs}

The USGS Maine Water Science Center will provide scoping-level time and cost estimates for the identified study needs for each water body listed in table 4. The time and cost estimates will include costs for hydrologic, hydraulic, and topographic data collection and analyses and mapping, depending on the identified type of study needed for each water body. The time and cost estimates will be submitted to the cooperating agencies (FEMA, Maine Floodplain Management Program) as a separate document as set forth in the scope of work.

\section{Project Alternatives}

Costs can be reduced by cutting back on the level of effort for the hydrologic and hydraulic $(\mathrm{H} \& \mathrm{H})$ analyses and (or) reducing the number of DFIRM panels.

Alternative H\&H options that would help FEMA to reduce costs include reducing the study scope from a detailed study to a limited detail study or redelineation of current flood information only. Reducing the number of DFIRM panels by altering the mix of panel scales would lower the total panel count and reduce the estimated DFIRM production cost. 


\section{Section 3. Options for Future Mapping and DTM Preparation}

\section{Mapping Requirements}

This section provides an assessment of the costs and benefits of utilizing the data cataloged in the previous section for the preparation of Digital Flood Insurance Rate Maps (DFIRMs) for Somerset County. Options are presented for using these data sets in various combinations and supplementing them with new data sets.

DFIRMs are produced from three broad categories of geospatial data: (1) Base Map, (2) Digital Terrain Model (DTM), and (3) Flood-Insurance Risk Zones. The spatial accuracy of each of these three categories is fixed by the specifications contained in the Guidelines and Specifications for Flood Hazard Mapping Partners, April 2003 (Guidelines and Specifications).

- Base Maps: Base maps are acquired from MEGIS and will be used by FEMA as a "backdrop" to the flood-insurance risk zones shown on the DFIRMs.

- Digital Terrain Models (DTMs): DTMs are used in conjunction with hydrologic and hydraulic models to interpret the limits of flood-insurance risk zones. DTMs represent terrain with irregularly-spaced spot elevations $(\mathrm{x}, \mathrm{y}, \mathrm{z})$ and breaklines that indicate changes in ground slope at features such as the toe or top of channel banks or ridge lines. These data sets are generally photogrametrically compiled by a mapping contractor from stereo photos and utilized in the form of a Triangulated Irregular Network (TIN) or a Digital Elevation Model (DEM). A DEM uses a regular grid, or raster, spacing of $(\mathrm{x}, \mathrm{y}, \mathrm{z})$ points to represent the land surface. Each grid cell is assigned an average elevation to represent the elevation of the ground that is covered by the grid cell. A DEM represents the terrain surface with a mesh of regularly spaced points, whereas a TIN uses contiguous triangular planes.

- Flood-Insurance Risk Zones: Geographic boundaries produced by FEMA and provided in digital format.

\section{Base Map}

Base maps are defined in the Guidelines and Specifications as the "map of the community that depicts cultural features (roads, railroad, bridges, dams, culverts), drainage features, and corporate limits." Depending on the source of the base map, the specific features found on DFIRMs may include the following data and features:

- Roads: centerlines, edge-of-pavement, right-of-way, names.

- Railroads: names.

- Bridges: names.

- Flood Control Structures: headwall, dam, levee, names.

- Airport Boundaries: names.

- Rivers: centerlines, banks, names.

- Streams: names. 
- Lakes: names.

- Political Boundaries: county, municipality, special districts, wards, military reservations, Native American lands, names.

- Land Use: parks, individual land parcels, names.

The Guidelines and Specifications specify "absolute horizontal accuracy" for base map features to establish horizontal accuracy for the position of the digital data set to its actual location on the earth's surface. The horizontal accuracy is specified as a statistical error distribution at the 95percent confidence level and is specified in the Guidelines and Specifications as a function of finished map scale, as shown in table 6:

Table 6. Flood Insurance Rate Map (FIRM) Horizontal Accuracy.

FIRM map scale Absolute horizontal accuracy at the 95-percent confidence level, in feet

\begin{tabular}{ll}
1 in $=500$ feet & 19.0 \\
1 in $=1,000$ feet & 38.0 \\
1 in $=2,000$ feet & 45.6 \\
\hline
\end{tabular}

MEGIS can provide digital data base mapping data for Somerset County for DFIRM production.

\section{Digital Terrain Models (DTMs)}

FEMA typically develops DTMs for the production of DFIRMS as they are not widely available at the accuracies required by FEMA. The DTMs are used in conjunction with hydrologic and hydraulic models to interpret flood boundaries and can be used by the community for many other purposes other than flood management.

Guidelines and Specifications identify the following four types of DTMs: (1) Digital contours, (2) Digital Elevation Models (DEMs), (3) Mass points and breaklines, and (4) Triangulated Irregular Networks (TIN). Each of these models can be created from the other and their use is application dependent.

Under FEMA guidelines, the allowable DTMs are as follows:

- Digital contours: continuous, nonintersecting lines of equal elevation separated by a specified elevation interval.

- Digital Elevation Model (DTM): $\mathrm{x}, \mathrm{y}$, and $\mathrm{z}$ coordinates of regularly spaced points that form a grid.

- Mass Points and Breaklines: $\mathrm{x}, \mathrm{y}$, and $\mathrm{z}$ coordinates of irregularly spaced points.

- Triangulated Irregular Network (TIN): contiguous triangles with $\mathrm{x}, \mathrm{y}$, and $\mathrm{z}$ values at the vertices and faces with slope and aspect. 
The Guidelines and Specifications specify what is referred to as "absolute vertical accuracy" for DTMs, which relates the elevation of the land surface in the digital data set to its actual elevation relative to a specific vertical datum. The National Standard for Spatial Data Accuracy (NSSDA) is specified as a statistical error distribution at the 90- and 95-percent confidence level as a function of the specified contour interval as shown in table 7:

Table 7. Horizontal Accuracy National Standard for Spatial Data

Accuracy (NSSDA).

\begin{tabular}{ccc}
$\begin{array}{c}\text { NSSDA Contour } \\
\text { interval }\end{array}$ & $\begin{array}{c}\text { NSSDA 90-percent } \\
\text { confidence interval }\end{array}$ & $\begin{array}{c}\text { NSSDA 95-percent } \\
\text { confidence interval }\end{array}$ \\
\hline 2 feet & 1 foot & 1.2 feet \\
4 feet & 2 feet & 2.4 feet \\
\hline
\end{tabular}

Contouring and DEMs are not printed on DFIRMS so their vertical accuracy is not labeled on the DFIRMS, but it is recorded in the metadata of elevation datasets used for hydrologic and hydraulic modeling.

Neither USGS nor MEGIS has elevation data suitable for hydraulic modeling and communities were contacted to find topographic or elevation data suitable for hydraulic modeling (e.g. 2-foot or 4-foot contours). Community specific topographic data will be used if it meets FEMA standards. New elevation data will be developed as necessary.

DTM development options include (1) obtaining countywide DTM data that covers all communities and (2) obtaining DTM data only for selected floodplain areas as needed to support a detailed study, limited detailed study, restudy or re-delineation of flood hazard areas. Obtaining DTM data on a countywide basis is expensive; most of the acquired data would be outside of the floodplain and not needed for hydraulic analysis. If FEMA obtains new DTM data for selected areas as needed, keeping in mind that is most cost effective to consolidate areas, where possible, and optimizes flights, the unit costs could be reduced.

\section{Flood-Insurance Risk Zones}

Flood-insurance risk zones are created by FEMA to set insurance rates and manage the floodplain. Flood-insurance risk zone accuracy requirements are not specified in the Guidelines and Specifications but can be described in terms of the combined accuracies of the base map, DTM, and the hydrology and hydraulic simulation models.

FEMA flood insurance rate 100- and 500-year flood zones are being converted to digital data layers by MEGIS for each community participating in the National Flood Insurance Program (NFIP) in Maine. These datasets were developed by direct digitization of FIRM maps using data registration techniques that produced the best-fit registration to community boundaries or other suitable features.

The most common comment by community representatives was that a better base map is needed to allow easier determination of where the risk zone boundaries are relative to the existing features such as roads and buildings. 


\section{Section 4. References Cited}

Burm, J.D., 2005, Pre-Scoping Report for Somerset County, March 2005: Mapping On Demand, NSP Task Order 0004 Deliverable, $101 \mathrm{p}$.

University of Maine, 2004, Maine census data, population totals: Fogler Library, University of Maine, accessed on September 16, 2004 at http://www.library.umaine.edu/census/

U.S. Census Bureau, 2002, Maine 2000: Summary population and housing characteristics: 2000 Census of Population and Housing, PH-1-21, 275 p. 
Appendixes 
Appendix A: Community Assistance Contacts and Visits: Somerset County 


\section{Community Assistance Contacts in Somerset County}

As of $12 / 2005$

BINGHAM, TOWN OF

Open Date Agency Conducted By Type Closed_Date

3/17/1995 STATE BCB PHONE 7/3/1995

CAMBRIDGE, TOWN OF

9/8/1994 STATE TJK PHONE 10/7/1994

CANAAN, TOWN OF

11/29/1993 STATE TJK PHONE 12/20/1993

EMBDEN, TOWN OF

8/24/1998 STATE Sb PHONE 6/2/1999

FAIRFIELD, TOWN OF

\begin{tabular}{|c|c|c|c|c|}
\hline $8 / 30 / 1993$ & STATE & EC & PHONE & \\
\hline $7 / 2 / 2001$ & STATE & sue baker & PHONE & $2 / 7 / 2002$ \\
\hline
\end{tabular}

HARMONY, TOWN OF

$\begin{array}{lllll}\text { 9/15/1994 } & \text { STATE } & \text { BCB } & \text { PHONE } & 10 / 3 / 1994 \\ 9 / 30 / 1998 & \text { STATE } & \text { SB } & \text { PHONE } & 5 / 10 / 2000\end{array}$

HARTLAND, TOWN OF

9/24/1998 STATE SB PHONE 10/21/1999

JACKMAN, TOWN OF

$\begin{array}{lllll}11 / 9 / 1992 & \text { STATE } & \text { TJK } & \text { PHONE } & 12 / 9 / 1992 \\ 8 / 19 / 2003 & \text { STATE } & \text { SLB } & \text { PHONE } & \end{array}$

MADISON, TOWN OF

3/23/1994 STATE TJK PHONE 5/5/1994

MERCER, TOWN OF

8/4/1994 STATE BCB PHONE 8/29/1994

MOScow, TOWN OF

7/29/1996 STATE Sb PHONE

NEW PORTLAND, TOWN OF

4/17/1991 STATE TK PHONE 4/25/1991

PALMYRA, TOWN OF

$\begin{array}{lllll}\text { 8/29/1994 } & \text { STATE } & \text { BCB } & \text { PHONE } & \text { 10/7/1994 } \\ \text { 9/25/2000 } & \text { STATE } & \text { sue baker } & \text { PHONE } & 2 / 8 / 2001\end{array}$

PITTSFIELD, TOWN OF

8/30/1993 STATE TJK PHONE

RIPLEY, TOWN OF

9/20/1996 STATE Sb PHONE




\begin{tabular}{|c|c|c|c|c|c|}
\hline \multirow{3}{*}{ SKOWHEGAN, TOWN OF } & Open Date & Agency & Conducted By & Type & Closed_Date \\
\hline & & & & & \\
\hline & $11 / 23 / 1993$ & STATE & TJK & PHONE & $12 / 3 / 1993$ \\
\hline \multicolumn{6}{|l|}{ SMITHFIELD, TOWN OF } \\
\hline & 9/8/1994 & STATE & $\mathrm{BCB}$ & PHONE & $10 / 3 / 1994$ \\
\hline \multicolumn{6}{|l|}{ ST. ALBANS, TOWN OF } \\
\hline & $7 / 21 / 1995$ & STATE & SB & PHONE & $8 / 11 / 1995$ \\
\hline & $9 / 30 / 2003$ & STATE & SLB & PHONE & \\
\hline \multicolumn{6}{|l|}{ STARKS, TOWN OF } \\
\hline & $12 / 30 / 1992$ & STATE & TJK & PHONE & $1 / 19 / 1993$ \\
\hline
\end{tabular}

As of 12/2005

$\begin{array}{lllll}\text { BINGHAM, TOWN OF } & \text { Open Date } & \text { Agency } & \text { Conducted By Closed_Date } \\ \text { FAIRFIELD, TOWN OF } & 9 / 26 / 2002 & \text { STATE } & \text { Lou Sidell } \\ \text { HARMONY, TOWN OF } & 8 / 29 / 1995 & \text { STATE } & \text { WLS } \\ \text { HARTLAND, TOWN OF } & 10 / 18 / 1999 & \text { STATE } & \text { WLS } \\ \text { SKOWHEGAN, TOWN OF } & 9 / 28 / 2004 & \text { STATE } & \text { W. Louis } & 4 / 1 / 2005 \\ & 1 / 21 / 2003 & \text { STATE } & \text { Lou Sidell }\end{array}$


Appendix B: Community Contacts and Best Available Data: Somerset County 
COMMUNITY CONTACTS AND BEST AVAILABLE DATA: SOMERSET COUNTY

\section{Anson, Town of}

Map Type: Floodways

Participating $=$ Yes LURC: No

Total No. NFIP Policies $=20$ No. Claims Since 1978 $=24$

Community Official Contact Information:

Robert Worthley 207-696-3979

Selectmen

Town of Anson

PO Box 297

Anson

ME $\quad 04911$

Community Code Enforcement Contact Information:

David Hartigan, CEO 207-696-3919

P.0. Box 86

Anson

ME 04911

Maine Floodplain Mgt. Prog. Best Available Data and supporting information:

Best Available Data: ND

Mapping Status: ND

Mapping Needs: ND
CID $230123 \quad$ Community Profile

Ordinance Date:

All LOMCs: $\odot$ 
COMMUNITY CONTACTS AND BEST AVAILABLE DATA: SOMERSET COUNTY

\section{Athens, Town of}

Map Type: Unnumbered A-Zone

Participating $=S \quad$ LURC: No

Total No. NFIP Policies=ND No. Claims Since 1978= ND

Community Official Contact Information:

Brent Foss 207-654-3471

Selectmen

Town of Athens

PO Box 147

Athens ME 04912

Community Code Enforcement Contact Information:

Kenneth Hogate, CEO 207-474-8865

161 West Ridge Rd

Cornville ME $\quad 04976$

Maine Floodplain Mgt. Prog. Best Available Data and supporting information:

Best Available Data:Great Moose Lake: Bfe 250.6' (ACE 12/95)

Mapping Status: ND

Mapping Needs: ND
CID 230354 Community Profile

All LOMCs: $\odot$ 
COMMUNITY CONTACTS AND BEST AVAILABLE DATA: SOMERSET COUNTY

\section{Bingham, Town of}

Map Type: Unnumbered A-Zone

Participating $=$ Yes LURC: No

Total No. NFIP Policies $=4 \quad$ No. Claims Since 1978= 1

Current FIRM/FIS Map Date: 9/27/1985

Ordinance Date: 3/7/1994

Community Official Contact Information:

Steven Steward 207-672-5519

Selectmen

Town of Bingham

PO Box 652

Bingham ME 04920

Community Code Enforcement Contact Information:

Timothy Andrews, CEO 207-672-5519

12 Somerset Ln

Bingham ME 04920

Maine Floodplain Mgt. Prog. Best Available Data and supporting information:

Best Available Data:Austin Stream, Bfe: (11/69 SCS)

Mapping Status: To be assigned to USGS for ' 98 studies. Check to see if NRCS ever took action.

Mapping Needs: '78 map more accurate than 85 map. 87 didn't flood many areas on panels $1 \& 4.85$ map no reality

S, Suspended; ND, No Data; NSFHA, No Specific Flood Hazard Area 
COMMUNITY CONTACTS AND BEST AVAILABLE DATA: SOMERSET COUNTY

\section{Cambridge, Town of}

Map Type: Unnumbered A-Zone

Participating $=$ Yes LURC: No

Total No. NFIP Policies=ND No. Claims Since 1978= ND

Community Official Contact Information:

Carol Laplant 207-277-3241

Selectmen

Town of Cambridge

202 Ripley Rd.

Cambridge ME 04923

Community Code Enforcement Contact Information:

William Murphy, CEO 207-938-4568

38 Guilford Rd

Cambridge ME 04923

Maine Floodplain Mgt. Prog. Best Available Data and supporting information:

Best Available Data: Cambridge Pond: Bfe 353.5' (ACE12/95.)

Mapping Status: ND

Mapping Needs: ND
CID 230355

Community Profile

Current FIRM/FIS Map Date: 9/27/1985

Ordinance Date: 6/4/1987

All LOMCs: $\odot$ 
COMMUNITY CONTACTS AND BEST AVAILABLE DATA: SOMERSET COUNTY

\section{Canaan, Town of}

CID 230356

Community Profile

Map Type: Unnumbered A-Zone

Current FIRM/FIS Map Date: 9/27/1985

Participating $=$ Yes LURC: No

Ordinance Date: 3/19/1994

Total No. NFIP Policies $=11$ No. Claims Since $1978=0$

All LOMCs: 2

Community Official Contact Information:

Louise Townsend 207-474-8976

Selectmen

Town of Canaan

PO Box 68

Canaan ME 04924

Community Code Enforcement Contact Information:

Randall Gray, CEO 207-474-6904

225 Water St

Skowhegan ME 04976

Maine Floodplain Mgt. Prog. Best Available Data and supporting information:

Best Available Data:Sibley Pond: 235.8' (?) (ACE 11/96)

Mapping Status: ND

Mapping Needs: ND

S, Suspended; ND, No Data; NSFHA, No Specific Flood Hazard Area 
COMMUNITY CONTACTS AND BEST AVAILABLE DATA: SOMERSET COUNTY

\section{Caratunk, Town of}

Map Type: Unnumbered A-Zone

Participating=Yes LURC: No

Total No. NFIP Policies $=4 \quad$ No. Claims Since 1978= 1

Community Official Contact Information:

ND

Community Code Enforcement Contact Information:

Will

Kershner, CEO

$207-672-3203$

P.0. Box 80

Caratunk ME 04925

Maine Floodplain Mgt. Prog. Best Available Data and supporting information:

Best Available Data: ND

Mapping Status: ND

Mapping Needs: ND
CID $230539 \quad$ Community Profile

Current FIRM/FIS Map Date: 11/1/1985

Ordinance Date: 5/13/1987

All LOMCs: $\odot$ 
COMMUNITY CONTACTS AND BEST AVAILABLE DATA: SOMERSET COUNTY

\section{Concord TWP}

Map Type: Unnumbered A-Zone

Participating $=$ Yes LURC: Yes

Total No. NFIP Policies $=1 \quad$ No. Claims Since 1978= 0

Community Official Contact Information:

Fred Todd

Manager

Land Use Regulatory Commission

SHS 22

Augusta

CID 230466

Community Profile

Current FIRM/FIS Map Date: 2/1/1985

Ordinance Date:

All LOMCs: 1

Community Code Enforcement Contact Information:

LURC

Maine Floodplain Mgt. Prog. Best Available Data and supporting information:

Best Available Data:Kennebec River BAD per Bingham draft FIRM

Mapping Status: ND

Mapping Needs: ND

S, Suspended; ND, No Data; NSFHA, No Specific Flood Hazard Area 
COMMUNITY CONTACTS AND BEST AVAILABLE DATA: SOMERSET COUNTY

\section{Cornville, Town of}

Map Type: Unnumbered A-Zone

Participating $=$ Yes LURC: No

Total No. NFIP Policies=ND No. Claims Since 1978= ND

Community Official Contact Information:

ND

Community Code Enforcement Contact Information:

Kenneth Hogate, CEO 207-474-8865

161 West Ridge Rd

Cornville ME 04976

Maine Floodplain Mgt. Prog. Best Available Data and supporting information:

Best Available Data: ND

Mapping Status: ND

Mapping Needs: ND
CID 230358

Community Profile

Current FIRM/FIS Map Date: 9/27/1985

Ordinance Date: 4/20/1987

All LOMCs: $\odot$ 
COMMUNITY CONTACTS AND BEST AVAILABLE DATA: SOMERSET COUNTY

\section{Detroit, Town of}

Map Type: Unnumbered A-Zone

Participating $=$ Yes LURC: No

Total No. NFIP Policies $=1 \quad$ No. Claims Since 1978= 0

Community Official Contact Information:

Joseph Cianchette 207-257-4488

Selectmen

Town of Detroit

35 South Main St.

Detroit ME 04929

Community Code Enforcement Contact Information:

ND

Maine Floodplain Mgt. Prog. Best Available Data and supporting information:

Best Available Data: ND

Mapping Status: ND

Mapping Needs: ND
CID 230357

Community Profile

Current FIRM/FIS Map Date: 8/19/1985

Ordinance Date: 6/27/1988

All LOMCs: $\odot$ 
COMMUNITY CONTACTS AND BEST AVAILABLE DATA: SOMERSET COUNTY

\section{Embden, Town of}

Map Type: Unnumbered A-Zone

Participating $=$ Yes LURC: No

Total No. NFIP Policies=ND No. Claims Since 1978= ND

Community Official Contact Information:

Raymond Young Sr. 207-635-2742

Selectmen

Town of Embden

659 Embden Pond Rd.

Embden ME 04958

Community Code Enforcement Contact Information:

Dwight Barron, Jr., CEO 207-635-2962

480 Embden Pond Rd

Embden ME 04958

Maine Floodplain Mgt. Prog. Best Available Data and supporting information:

Best Available Data: ND

Mapping Status: ND

Mapping Needs: ND
CID 230359

Community Profile

Ordinance Date: 3/5/1994

All LOMCs: 1 
COMMUNITY CONTACTS AND BEST AVAILABLE DATA: SOMERSET COUNTY

\section{Fairfield, Town of}

Map Type: Floodways

Participating $=$ Yes LURC: No

Total No. NFIP Policies $=46$ No. Claims Since 1978 $=20$

Current FIRM/FIS Map Date: 2/17/1988

Ordinance Date: $2 / 9 / 2005$

All LOMCs: $\odot$

Community Official Contact Information:

Chris Huck 207-453-4258

Kennebec Valley Council of Govt.

17 Main St.

Fairfield ME 04937

Community Code Enforcement Contact Information:

Cynthia Tuttle, CEO 207-453-7765

PO Box 149

Fairfield ME 04937

Maine Floodplain Mgt. Prog. Best Available Data and supporting information:

Best Available Data: ND

Mapping Status: ND

Mapping Needs: ND

S, Suspended; ND, No Data; NSFHA, No Specific Flood Hazard Area 
COMMUNITY CONTACTS AND BEST AVAILABLE DATA: SOMERSET COUNTY

\section{Harmony, Town of}

Map Type: Unnumbered A-Zone

Participating $=$ Yes LURC: No

Total No. NFIP Policies $=3 \quad$ No. Claims Since 1978 $=2$

Community Official Contact Information:

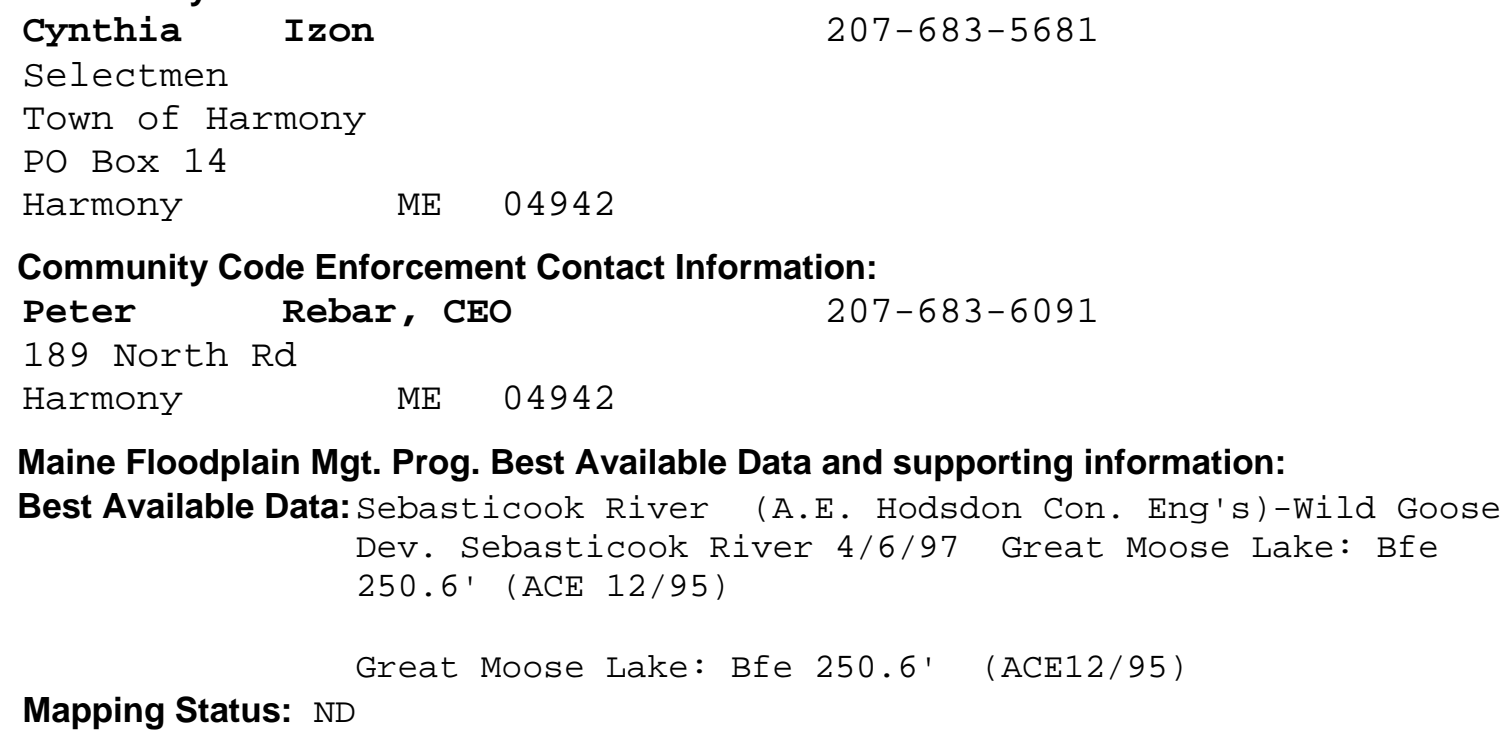

Community Code Enforcement Contact Information:

\section{Peter \\ 189 North Rd}

Harmony

Maine Floodplain Mgt. Prog. Best Available Data and supporting information:

Best Available Data:Sebasticook River (A.E. Hodsdon Con. Eng's)-Wild Goose Dev. Sebasticook River 4/6/97 Great Moose Lake: Bfe 250.6' (ACE 12/95)

Mapping Status: ND

$$
\text { Great Moose Lake: Bfe 250.6' (ACE12/95) }
$$

CID 230360

Community Profile
Current FIRM/FIS Map Date: 9/27/1985

Ordinance Date: 3/18/1995

Mapping Needs: ND

S, Suspended; ND, No Data; NSFHA, No Specific Flood Hazard Area 
COMMUNITY CONTACTS AND BEST AVAILABLE DATA: SOMERSET COUNTY

\section{Hartland, Town of}

Map Type: Unnumbered A-Zone

Participating=Yes LURC: No

Total No. NFIP Policies $=27$ No. Claims Since $1978=4$

Community Official Contact Information:

Peggy Morgan
Town Manager
Town of Hartland
PO Box 280
Hartland ME $\quad 04943$

Community Code Enforcement Contact Information:

William Murphy, CEO 207-938-4568

38 Guilford Rd

Cambridge ME 04923

Maine Floodplain Mgt. Prog. Best Available Data and supporting information:

Best Available Data: Sebasticook River (ACE 1/96) Great Moose Lake: Bfe 250.6' (ACE 1/95) Morrill Pond: Bfe 300.6' (Hartland LOMA 4/27/01) Sebasticook River-All structures on water Street: Bfe 240' (ACE 1990, 84 \& 95)

Great Moose Lake: Bfe 250.6' (ACE 1/96)

Sebasticook River at Mill St. bridge per MDOT: Bfe 242' (12/99)

Mapping Status: D\&D will look at for XDS projects in '97/'98.

Mapping Needs: town requested updated maps 11/27/95 and 4/1/97 and Lou sent support letter to Region $12 / 2 / 95$ and $4 / 10 / 97$

S, Suspended; ND, No Data; NSFHA, No Specific Flood Hazard Area 
COMMUNITY CONTACTS AND BEST AVAILABLE DATA: SOMERSET COUNTY

\section{Jackman, Town of}

Map Type: Unnumbered A-Zone

Participating $=$ Yes LURC: No

Total No. NFIP Policies $=3 \quad$ No. Claims Since 1978= 0

Community Official Contact Information:

Kathleen MacKenzie 207-668-2111

Town Manager

Town of Jackman

PO Box 269

Jackman

ME $\quad 04945$

Community Code Enforcement Contact Information:

James Schoenmann, CEO

$207-668-4461$

7 Attean Rd

Jackman

ME $\quad 04945$

Maine Floodplain Mgt. Prog. Best Available Data and supporting information:

Best Available Data: Long Pond: Bfe 1161' (ACE 12/86) Wood Pond: Bfe 1163 (ACE 12/86)

Mapping Status: ND

Wood Pond: Bfe 1163' (ACE 8-27-96)

Mapping Needs: ND
All LOMCs: 2
Community Profile

Current FIRM/FIS Map Date: 9/4/1985

Ordinance Date: 3/19/1987 
COMMUNITY CONTACTS AND BEST AVAILABLE DATA: SOMERSET COUNTY

\section{Madison, Town of}

Map Type: Floodways

Participating $=$ Yes LURC: No

Total No. NFIP Policies $=13$ No. Claims Since 1978= 4

Community Official Contact Information:

Norman Dean 207-696-3971

Town Manager

Town of Madison

PO Box 190

Madison $\quad$ ME 04950

Community Code Enforcement Contact Information:

Robert Dunphy, CEO 207-635-2593

PO Box 70

North Anson ME 04911

Maine Floodplain Mgt. Prog. Best Available Data and supporting information:

Best Available Data: ND

Mapping Status: ND

Mapping Needs: ND
CID 230126

Community Profile
Ordinance Date: 4/4/1995 
COMMUNITY CONTACTS AND BEST AVAILABLE DATA: SOMERSET COUNTY

\section{Mercer, Town of}

CID 230176

Community Profile

Map Type: No Floodways

Current FIRM/FIS Map Date: 5/2/1994

Participating=Yes LURC: No

Ordinance Date: 3/5/1994

Total No. NFIP Policies=ND No. Claims Since 1978= ND

All LOMCs: 1

Community Official Contact Information:

ND

Community Code Enforcement Contact Information:

Michael Zarcone, CEO 207-362-2611

P0 Box 68

Smithfield ME 04978

Maine Floodplain Mgt. Prog. Best Available Data and supporting information:

Best Available Data: ND

Mapping Status: ND

Mapping Needs: ND

S, Suspended; ND, No Data; NSFHA, No Specific Flood Hazard Area 
COMMUNITY CONTACTS AND BEST AVAILABLE DATA: SOMERSET COUNTY

\section{Moose River, Town of}

Map Type: Unnumbered A-Zone

Participating $=$ No LURC: No

Total No. NFIP Policies=ND No. Claims Since 1978= ND

Community Official Contact Information:

Sterling Reed

Selectmen

Town of Moose River

724 Main St.

Moose River ME 04945

Community Code Enforcement Contact Information:

Carl Mairhuber, CEO

PO Box 25 Marston St

Jackman

ME 04945

Maine Floodplain Mgt. Prog. Best Available Data and supporting information:

Best Available Data: ND

Mapping Status: ND

Mapping Needs: ND
CID 230363

Community Profile
Current FIRM/FIS Map Date: 1/17/1975

Ordinance Date: 
COMMUNITY CONTACTS AND BEST AVAILABLE DATA: SOMERSET COUNTY

\section{Moscow, Town of}

Map Type: Unnumbered A-Zone

Participating $=$ Yes LURC: No

Total No. NFIP Policies $=1 \quad$ No. Claims Since 1978= 1

Community Official Contact Information:

Donald Beane 207-672-4834

Selectmen

Town of Moscow

110 Canada Rd.

Moscow

ME $\quad 04920$

Community Code Enforcement Contact Information:

Timothy Andrews, CEO 207-672-5519

12 Somerset Ln

Bingham ME 04920

Maine Floodplain Mgt. Prog. Best Available Data and supporting information:

Best Available Data: Austin Stream (SCS 11/69)

Mapping Status: ND

Mapping Needs: ND
CID $230364 \quad$ Community Profile

Current FIRM/FIS Map Date: 11/1/1985

Ordinance Date: 5/21/1987

All LOMCs: $\odot$ 
COMMUNITY CONTACTS AND BEST AVAILABLE DATA: SOMERSET COUNTY

\section{New Portland, Town of}

Map Type: Unnumbered A-Zone

Participating $=$ Yes LURC: No

Total No. NFIP Policies $=10$ No. Claims Since 1978= 1

Community Official Contact Information:

Andrea Reichert 207-628-4441

Town Manager

Town of New Portland

PO Box 629

New Portland ME 04954

Community Code Enforcement Contact Information:

Robert Dunphy, CEO

PO Box 70

North Anson

ME $\quad 04911$
CID 230365 Community Profile

Current FIRM/FIS Map Date: 8/19/1985

Ordinance Date: 5/28/1987

Maine Floodplain Mgt. Prog. Best Available Data and supporting information:

Best Available Data: ND

Mapping Status: ND

Mapping Needs: Town has requested detailed study - 2 dams removed, some data due to subdivisions (Sackett \& Brake), development pressures, need bfes

S, Suspended; ND, No Data; NSFHA, No Specific Flood Hazard Area 
COMMUNITY CONTACTS AND BEST AVAILABLE DATA: SOMERSET COUNTY

\section{Norridgewock, Town of}

Map Type: Floodways

Participating $=$ Yes LURC: No

Total No. NFIP Policies $=26$ No. Claims Since 1978= 18

Community Official Contact Information:

Norman Redlevske 207-587-2911

Selectmen

Town of Mercer

Main St., RR 2, Box 899

Norridgewock ME 04957

Community Code Enforcement Contact Information:

Robert Dunphy, CEO 207-635-2593

PO Box 70

North Anson ME 04911

Maine Floodplain Mgt. Prog. Best Available Data and supporting information:

Best Available Data: ND

Mapping Status: ND

Mapping Needs: ND
CID $230178 \quad$ Community Profile

Current FIRM/FIS Map Date: 5/6/1996

Ordinance Date: 6/24/1996

All LOMCs: 1 
COMMUNITY CONTACTS AND BEST AVAILABLE DATA: SOMERSET COUNTY

\section{Palmyra, Town of}

Map Type: Unnumbered A-Zone

Participating $=$ Yes LURC: No

Total No. NFIP Policies $=4$

No. Claims Since $1978=0$

Current FIRM/FIS Map Date: 8/19/1985

Ordinance Date: 6/9/1987

Community Official Contact Information:

Diane Abbott-Cookson 207-938-4871

Selectmen

Town of Palmyra

PO Box 6

Palmyra ME 04965

Community Code Enforcement Contact Information:

William Murphy, CEO 207-938-4568

38 Guilford Rd

Cambridge ME 04923

Maine Floodplain Mgt. Prog. Best Available Data and supporting information:

Best Available Data:Sebasticook River: (ACE 12/95) Flood Elevation Determination Whites Pond: Bfe 271.4' ( $3 / 99$ - NRCS wildlifestudy). Replacem't dam may make Bfe goup to 272 . Douglas Pond: Bfe 220.5 (12/95 ACE) Flood Elevation Determination

Mapping Status: ND

Mapping Needs: ND 
COMMUNITY CONTACTS AND BEST AVAILABLE DATA: SOMERSET COUNTY

\section{Pittsfield, Town of}

Map Type: Floodways

Participating $=$ Yes LURC: No

Total No. NFIP Policies $=20 \quad$ No. Claims Since 1978 $=11$

Community Official Contact Information:

Kathryn Ruth

Town Manager

Town of Pittsfield

16 Park St.

Pittsfield ME 04967

Community Code Enforcement Contact Information:

ND

Maine Floodplain Mgt. Prog. Best Available Data and supporting information:

Best Available Data:Sebasticook River (ACE 12/95) Sibley Pond: 235.8'? (ACE 11/96)

Mapping Status: ND

Mapping Needs: ND
Current FIRM/FIS Map Date: 1/19/1996

Ordinance Date: 6/6/2000

All LOMCs: 3 
COMMUNITY CONTACTS AND BEST AVAILABLE DATA: SOMERSET COUNTY

\section{Pleasant Ridge PLT}

Map Type: Unnumbered A-Zone

Participating $=$ Yes LURC: Yes

Total No. NFIP Policies=ND No. Claims Since 1978= ND

Community Official Contact Information:

Fred Todd

Manager

Land Use Regulatory Commission

SHS 22

Augusta

CID 230367

Community Profile

Current FIRM/FIS Map Date: 11/1/1985

Ordinance Date:

All LOMCs: $\odot$

Community Code Enforcement Contact Information:

LURC

Maine Floodplain Mgt. Prog. Best Available Data and supporting information:

Best Available Data: ND

Mapping Status: ND

Mapping Needs: ND

S, Suspended; ND, No Data; NSFHA, No Specific Flood Hazard Area 
COMMUNITY CONTACTS AND BEST AVAILABLE DATA: SOMERSET COUNTY

\section{Ripley, Town of}

CID 230368

Community Profile

Map Type: Unnumbered A-Zone

Current FIRM/FIS Map Date: 9/27/1985

Participating $=$ Yes LURC: No

Ordinance Date: 5/15/1987

Total No. NFIP Policies $=1 \quad$ No. Claims Since 1978 $=0$

All LOMCs: $\odot$

Community Official Contact Information:

Dorothy Hutchins 207-288-4871

Selectmen

Town of Ripley

1084 Main St.

Ripley ME 04930

Community Code Enforcement Contact Information:

Travis Gould, CEO 207-277-5344

211 North Rd

Ripley ME 04930

Maine Floodplain Mgt. Prog. Best Available Data and supporting information:

Best Available Data:Ripley Pond: Bfe 440.5' (ACE 10/26/94)

Mapping Status: ND

Mapping Needs: ND

S, Suspended; ND, No Data; NSFHA, No Specific Flood Hazard Area 
COMMUNITY CONTACTS AND BEST AVAILABLE DATA: SOMERSET COUNTY

\section{Rockwood Strip TWP, T01 R01 NBKP CID 230467 Community Profile}

Map Type: Unnumbered A-Zone

Participating $=$ Yes LURC: Yes

Total No. NFIP Policies=ND No. Claims Since 1978= ND

Community Official Contact Information:

Fred Todd

Manager

Land Use Regulatory Commission

SHS 22

Augusta
Current FIRM/FIS Map Date: 12/1/1987

Ordinance Date:

All LOMCs: $\odot$

Community Code Enforcement Contact Information:

LURC

Maine Floodplain Mgt. Prog. Best Available Data and supporting information:

Best Available Data: Moosehead Lake: Bfe 1029.5 (Greenville FIs 9/7/01)

Mapping Status: ND

Mapping Needs: ND

S, Suspended; ND, No Data; NSFHA, No Specific Flood Hazard Area 
COMMUNITY CONTACTS AND BEST AVAILABLE DATA: SOMERSET COUNTY

\section{Skowhegan, Town of}

Map Type: Floodways

Participating $=$ Yes LURC: No

Total No. NFIP Policies=35 No. Claims Since 1978=14

Community Official Contact Information:

Robert Higgins Sr.

$207-474-9861$

Somerset County Emergency Mgt

Court House

Skowhegan ME 04976

Community Code Enforcement Contact Information:

Randall G 25 Water St

Skowhegan

Gray, CEO

$207-474-6904$

CID 230128

Community Profile

Current FIRM/FIS Map Date: 9/20/1995

Ordinance Date: $3 / 12 / 2001$

All LOMCs: 2

Maine Floodplain Mgt. Prog. Best Available Data and supporting information:

Best Available Data: ND

Mapping Status: ND

Mapping Needs: Substantial horizontal error in base map for the FIRM thus there are concerns in the 1989 and 1995 Flood Insurance Studies regarding the vertical measurements. Horizontal error may be as much as 60' and confirmed by surveyors during the establishment of BFE's for clients.

S, Suspended; ND, No Data; NSFHA, No Specific Flood Hazard Area 
COMMUNITY CONTACTS AND BEST AVAILABLE DATA: SOMERSET COUNTY

\section{Smithfield, Town of}

Map Type: Unnumbered A-Zone

Participating $=$ Yes LURC: No

Total No. NFIP Policies $=2 \quad$ No. Claims Since 1978= 0

Current FIRM/FIS Map Date: 9/4/1985

Ordinance Date: 5/12/1990

Community Official Contact Information:

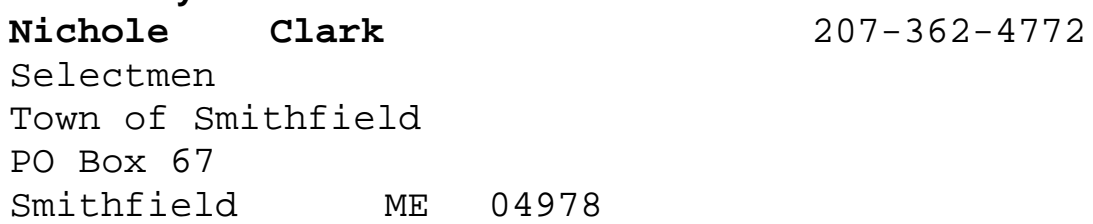

Community Code Enforcement Contact Information:

Kenneth Hogate, CEO 207-474-8865

161 West Ridge Rd

Cornville ME $\quad 04976$

Maine Floodplain Mgt. Prog. Best Available Data and supporting information:

Best Available Data: North Pond: 256' (Mercer FIRM 5/2/94)

Mapping Status: ND

Mapping Needs: ND
All LOMCs: $\odot$ 
COMMUNITY CONTACTS AND BEST AVAILABLE DATA: SOMERSET COUNTY

\section{Solon, Town of}

Map Type: Unnumbered A-Zone

Participating $=$ Yes LURC: No

Total No. NFIP Policies $=1 \quad$ No. Claims Since 1978= 0

Current FIRM/FIS Map Date: 8/19/1985

Ordinance Date: 3/7/1987

Community Official Contact Information:

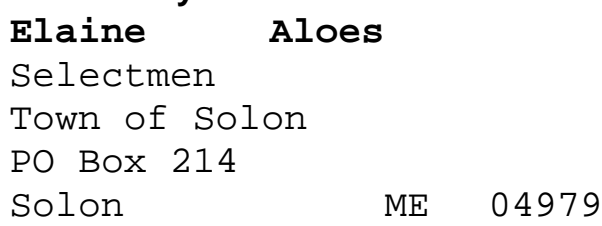

Community Code Enforcement Contact Information:

Kenneth Hogate, CEO 207-474-8865

161 West Ridge Rd

Cornville ME 04976

Maine Floodplain Mgt. Prog. Best Available Data and supporting information:

Best Available Data: ND

Mapping Status: ND

Mapping Needs: ND
All LOMCs: $\odot$ 
COMMUNITY CONTACTS AND BEST AVAILABLE DATA: SOMERSET COUNTY

St. Albans, Town of

Map Type: Unnumbered A-Zone

Participating $=$ Yes LURC: No

Total No. NFIP Policies $=20 \quad$ No. Claims Since 1978= 1

Community Official Contact Information:

$\begin{array}{lll}\text { Larry Post 207-938-4568 } & \end{array}$

Town Manager

Town of St Albans

PO Box 100

St. Albans ME 04971

Community Code Enforcement Contact Information:

William Murphy, CEO 207-938-4568

38 Guilford Rd

Cambridge ME 04923

Maine Floodplain Mgt. Prog. Best Available Data and supporting information:

Best Available Data: Great Moose Lake: Bfe 250.6' (ACE 12/95) Big Indian Pond: Bfe 271' (SCS 10/91) Little Indian Pond: Bfe 271' Weymouth Pond: Bfe 299' Indian Stream Ray Brook (see more) Meloon Brook Bog Brook (SCS 10/91)

Mapping Status: D\&D will look at for XDS projects in '97/'98.

Mapping Needs: ND

S, Suspended; ND, No Data; NSFHA, No Specific Flood Hazard Area 
COMMUNITY CONTACTS AND BEST AVAILABLE DATA: SOMERSET COUNTY

\section{Starks, Town of}

Map Type: Floodways

Participating=Yes LURC: No

Total No. NFIP Policies $=1 \quad$ No. Claims Since 1978= 0

Current FIRM/FIS Map Date: 5/20/1996

Ordinance Date: $3 / 11 / 2000$

Community Official Contact Information:

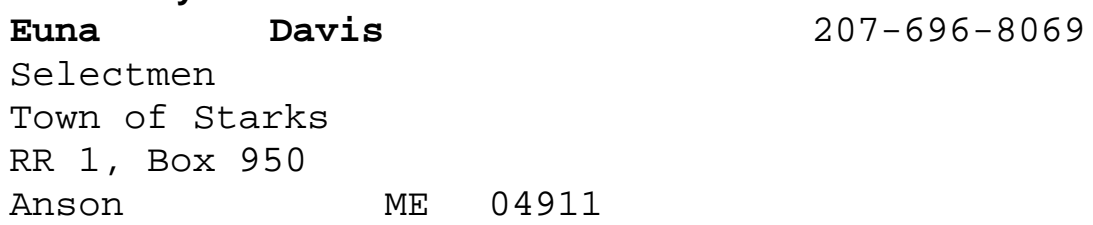

Community Code Enforcement Contact Information:

David Hartigan, CEO 207-696-3919

P.0. Box 86

Anson

ME 04911

Maine Floodplain Mgt. Prog. Best Available Data and supporting information:

Best Available Data: ND

Mapping Status: ND

Mapping Needs: ND
All LOMCs: 3 
Appendix C: Community Scoping Interview Data: Somerset County 
SCOPING INTERVIEW DATA FOR: Anson, Town of

CID: 230123 Council Govt: Annual Town Meeting Date:

Town Govt:

Community Representative Interviewed

Robert A. Dunphy

Code Enforcement officer

Email: rdunphy@tdstelme.net Tel: (207) 696-3979Fax:

Floodplain Management Community Contact (if different from above):

Known problems with flood maps for your community

Do you have specific areas that don't flood (1\% chance) but are currently in the floodplain? No

Do you have specific areas that flood ( $1 \%$ chance) but are not mapped in the floodplain? No

Note any significant changes in hydraulic structures (bridges, culverts, dams)

The dam was redone/washover boards were replaced with bladder type

Do you have (or are you proposing) high-development areas where you need new or restudied flood elevations or improved map scale?

No

\section{Community Resources}

Do you have aerial photography (or plans for any) (flight date, scale, color/bw)?

OGIS

Do you have any topographic data (or plans for collecting) (digital terrain, contour maps)? OGIS

Do you have any data related to hydrologic/hydraulic studies (or plans for such studies)? No

Do you have dedicated GIS capabilities (if so, provide contact information)? Yes

Notes 
SCOPING INTERVIEW DATA FOR: Athens, TOWn of

CID: 230354 Council Govt: Annual Town Meeting Date:

Town Govt: $\quad$ March

Community Representative Interviewed

Kenneth A. Hogate

Code Enforcement Officer

Email: bhogate@panax.com

Tel: (207) 474-8865Fax:

Floodplain Management Community Contact (if different from above):

Known problems with flood maps for your community

Do you have specific areas that don't flood (1\% chance) but are currently in the floodplain? No

Do you have specific areas that flood ( $1 \%$ chance) but are not mapped in the floodplain? No

Note any significant changes in hydraulic structures (bridges, culverts, dams)

No

Do you have (or are you proposing) high-development areas where you need new or restudied flood elevations or improved map scale?

No

Community Resources

Do you have aerial photography (or plans for any) (flight date, scale, color/bw)?

No

Do you have any topographic data (or plans for collecting) (digital terrain, contour maps)? No

Do you have any data related to hydrologic/hydraulic studies (or plans for such studies)? No

Do you have dedicated GIS capabilities (if so, provide contact information)?

No

Notes

First priority - West Athens Panel No. 7; most development along stream; may not be accurately mapped 
SCOPING INTERVIEW DATA FOR: Bingham, Town of

CID: 230124 Council Govt: Annual Town Meeting Date:

Town Govt:

Community Representative Interviewed

Frederica Meledes

Chairman Bingham Planning Board

Email: sam6722000@yahoo.com Tel: (207) 672-4853Fax:

Floodplain Management Community Contact (if different from above):

Known problems with flood maps for your community

Do you have specific areas that don't flood (1\% chance) but are currently in the floodplain? No

Do you have specific areas that flood ( $1 \%$ chance) but are not mapped in the floodplain? No

Note any significant changes in hydraulic structures (bridges, culverts, dams)

No

Do you have (or are you proposing) high-development areas where you need new or restudied flood elevations or improved map scale?

No

\section{Community Resources}

Do you have aerial photography (or plans for any) (flight date, scale, color/bw)?

Yes, old ones

Do you have any topographic data (or plans for collecting) (digital terrain, contour maps)? No

Do you have any data related to hydrologic/hydraulic studies (or plans for such studies)? No

Do you have dedicated GIS capabilities (if so, provide contact information)? No

Notes

New map will take care of this. Everything looks reasonable in BAD/minus database. Frederica Meledes is not the code officer, but her thought was that the new study on the Kennebec would take care of everything. 
SCOPING INTERVIEW DATA FOR: Cambridge, Town of

CID: 230355 Council Govt: Annual Town Meeting Date:

Town Govt:

Community Representative Interviewed

Oniz Lougez

Email:

Tel: (207) 683-5000Fax:

(207) 683-5401

Floodplain Management Community Contact (if different from above):

Known problems with flood maps for your community

Do you have specific areas that don't flood (1\% chance) but are currently in the floodplain?

Yes, Jimmy Brook and Ike Brook needs to be looked at in detail portions of these probably are not a hazard for flooding.

Do you have specific areas that flood ( $1 \%$ chance) but are not mapped in the floodplain? No

Note any significant changes in hydraulic structures (bridges, culverts, dams)

No

Do you have (or are you proposing) high-development areas where you need new or restudied flood elevations or improved map scale?

No

Community Resources

Do you have aerial photography (or plans for any) (flight date, scale, color/bw)? No

Do you have any topographic data (or plans for collecting) (digital terrain, contour maps)? No

Do you have any data related to hydrologic/hydraulic studies (or plans for such studies)? No

Do you have dedicated GIS capabilities (if so, provide contact information)? No

Notes 
SCOPING INTERVIEW DATA FOR: Canaan, Town of

CID: 230356 Council Govt: Annual Town Meeting Date:

Town Govt: $\quad$ March (3rd week)

Community Representative Interviewed

Randall D. Gray

Code Enforcement officer

Email: skowcode@skowhegan.org

Tel: (207) 474-6904Fax:

(207) 474-9413

Floodplain Management Community Contact (if different from above):

Known problems with flood maps for your community

Do you have specific areas that don't flood (1\% chance) but are currently in the floodplain?

Yes, only panel 4; No name stream Rt. 23 (Hartland Rd).

Do you have specific areas that flood ( $1 \%$ chance) but are not mapped in the floodplain?

Yes, panel 3; Blake Rd. crossing, Blackstream.

Note any significant changes in hydraulic structures (bridges, culverts, dams)

Yes, new culvert panel 3. NW corner; increased culvert from 2' to 4' and has helped, but may not affect 100 year.

Do you have (or are you proposing) high-development areas where you need new or restudied flood elevations or improved map scale?

Yes, village center on Carrabassett Stream, panel 8.

Community Resources

Do you have aerial photography (or plans for any) (flight date, scale, color/bw)?

No

Do you have any topographic data (or plans for collecting) (digital terrain, contour maps)? No

Do you have any data related to hydrologic/hydraulic studies (or plans for such studies)? No

Do you have dedicated GIS capabilities (if so, provide contact information)? No

Notes 
SCOPING INTERVIEW DATA FOR: Concord TWP

CID: 230466 Council Govt: Annual Town Meeting Date: Town Govt:

Community Representative Interviewed

Land Use Regulatory Commission

Email:

Tel:

Fax:

Floodplain Management Community Contact (if different from above):

Known problems with flood maps for your community

Do you have specific areas that don't flood (1\% chance) but are currently in the floodplain? No

Do you have specific areas that flood ( $1 \%$ chance) but are not mapped in the floodplain? No

Note any significant changes in hydraulic structures (bridges, culverts, dams) No

Do you have (or are you proposing) high-development areas where you need new or restudied flood elevations or improved map scale?

No

\section{Community Resources}

Do you have aerial photography (or plans for any) (flight date, scale, color/bw)?

No

Do you have any topographic data (or plans for collecting) (digital terrain, contour maps)? No

Do you have any data related to hydrologic/hydraulic studies (or plans for such studies)? No

Do you have dedicated GIS capabilities (if so, provide contact information)? No

Notes

Top priority: Need Kennebec River mapped using data from Bingham study (on other side of the river) 
SCOPING INTERVIEW DATA FOR: Cornville, Town of

CID: 230358 Council Govt: Annual Town Meeting Date:

Town Govt: $\quad$ March

Community Representative Interviewed

Kenneth A. Hogate

Code Enforcement Officer

Email: bhogate@panax.com

Tel: (207) 474-8865Fax:

Floodplain Management Community Contact (if different from above):

Known problems with flood maps for your community

Do you have specific areas that don't flood (1\% chance) but are currently in the floodplain? Yes, see marked Cornville map.

Do you have specific areas that flood ( $1 \%$ chance) but are not mapped in the floodplain? Yes, see map.

Note any significant changes in hydraulic structures (bridges, culverts, dams) No

Do you have (or are you proposing) high-development areas where you need new or restudied flood elevations or improved map scale?

No

Community Resources

Do you have aerial photography (or plans for any) (flight date, scale, color/bw)?

No

Do you have any topographic data (or plans for collecting) (digital terrain, contour maps)? No

Do you have any data related to hydrologic/hydraulic studies (or plans for such studies)? No

Do you have dedicated GIS capabilities (if so, provide contact information)? No

Notes

First priority: East Ridge Rd., panel \#2; Second priority: Walton Mills Rd., panel \#4; Third priority: Barker Pond, panel \#2 
SCOPING INTERVIEW DATA FOR: Embden, Town of

CID: 230359 Council Govt: Annual Town Meeting Date:

Town Govt: $\quad$ March

Community Representative Interviewed

Robert A. Dunphy

LPI

Email: rdunphy@tdstelme.net

Tel: (207) 431-2124Fax:

Floodplain Management Community Contact (if different from above):

Known problems with flood maps for your community

Do you have specific areas that don't flood (1\% chance) but are currently in the floodplain? No

Do you have specific areas that flood ( $1 \%$ chance) but are not mapped in the floodplain? No

Note any significant changes in hydraulic structures (bridges, culverts, dams)

No

Do you have (or are you proposing) high-development areas where you need new or restudied flood elevations or improved map scale?

No

Community Resources

Do you have aerial photography (or plans for any) (flight date, scale, color/bw)?

OGIS

Do you have any topographic data (or plans for collecting) (digital terrain, contour maps)?

OGIS

Do you have any data related to hydrologic/hydraulic studies (or plans for such studies)? No

Do you have dedicated GIS capabilities (if so, provide contact information)? Yes

Notes

Only Zone A are done; Map 4 - the culverts at the Martin Stream/Moulton Rd. crossing were replaced with larger one year?; Embden Pond dam has a huge leak; Map 9 - Fahi Pond \& most of Kennebec R. needs to be looked@

Maps were done in 1985 - very poor quality 
SCOPING INTERVIEW DATA FOR: Fairfield, Town of

CID: 230125 Council Govt: Annual Town Meeting Date:

Town Govt: $\quad$ 2nd Monday in May

Community Representative Interviewed

Cynthia Tuttle

CEO/Assessor

Email: ctuttle@fairfieldme.com

Tel: (207) 453-7765Fax: (207) 453-4280

Floodplain Management Community Contact (if different from above):

Known problems with flood maps for your community

Do you have specific areas that don't flood (1\% chance) but are currently in the floodplain?

No, accuracy pretty good; reflected 87 flood pretty well.

Do you have specific areas that flood ( $1 \%$ chance) but are not mapped in the floodplain?

No, see above

Note any significant changes in hydraulic structures (bridges, culverts, dams)

No, minor road reconstruction only.

Do you have (or are you proposing) high-development areas where you need new or restudied flood elevations or improved map scale?

No, nothing new. Only develoment is along Kennebec river, water st., downtown.

\section{Community Resources}

Do you have aerial photography (or plans for any) (flight date, scale, color/bw)?

Yes; E 911 data; photos only. 1990, pretty good, hard copies only; aerial survey and photo in Norrwidgewalk.

Do you have any topographic data (or plans for collecting) (digital terrain, contour maps)? No

Do you have any data related to hydrologic/hydraulic studies (or plans for such studies)? No

Do you have dedicated GIS capabilities (if so, provide contact information)?

No, couple years down the line.

Notes

Panel 25 B only panel the really use. Feels that the town does not have high priority needs. May not be worth doing this community for detailed study considering other needs in county. 
SCOPING INTERVIEW DATA FOR: Harmony, TOWn of

CID: 230360 Council Govt: Annual Town Meeting Date:

Town Govt:

Community Representative Interviewed

Onie D. Lougee

Planning Board Chairman

Email:

Tel: (207) 683-5000Fax: (207) 683-5401

Floodplain Management Community Contact (if different from above):

Known problems with flood maps for your community

Do you have specific areas that don't flood (1\% chance) but are currently in the floodplain?

Yes, see panel 6,5 and 8

Do you have specific areas that flood ( $1 \%$ chance) but are not mapped in the floodplain?

Yes, see panel 6,5 and 8

Note any significant changes in hydraulic structures (bridges, culverts, dams)

No

Do you have (or are you proposing) high-development areas where you need new or restudied flood elevations or improved map scale?

No

\section{Community Resources}

Do you have aerial photography (or plans for any) (flight date, scale, color/bw)?

No

Do you have any topographic data (or plans for collecting) (digital terrain, contour maps)? No

Do you have any data related to hydrologic/hydraulic studies (or plans for such studies)? No

Do you have dedicated GIS capabilities (if so, provide contact information)? No

Notes 
SCOPING INTERVIEW DATA FOR: Hartland, Town of

CID: 230361 Council Govt: Annual Town Meeting Date:

Town Govt:

Community Representative Interviewed

Marie S. Lougee

Surveyor

Email:

Tel: (207) 683-5000Fax:

(207) 683-5284

Floodplain Management Community Contact (if different from above):

Known problems with flood maps for your community

Do you have specific areas that don't flood (1\% chance) but are currently in the floodplain?

Yes, see maps $03,04,02$, and 01

Do you have specific areas that flood ( $1 \%$ chance) but are not mapped in the floodplain? No

Note any significant changes in hydraulic structures (bridges, culverts, dams)

No

Do you have (or are you proposing) high-development areas where you need new or restudied flood elevations or improved map scale?

No

\section{Community Resources}

Do you have aerial photography (or plans for any) (flight date, scale, color/bw)?

No

Do you have any topographic data (or plans for collecting) (digital terrain, contour maps)? No

Do you have any data related to hydrologic/hydraulic studies (or plans for such studies)? No

Do you have dedicated GIS capabilities (if so, provide contact information)? No

Notes 
SCOPING INTERVIEW DATA FOR:

CID: 230362
Council Govt:

Town Govt:

\section{Jackman, Town of}

Annual Town Meeting Date:

March

Community Representative Interviewed

Barbara Kane and James

P. Bd. Chair and Code Enf. Officer

Email: bakane@bordertrust.com

Tel: (207) 668-2111Fax:

(207) $668-3361$

Floodplain Management Community Contact (if different from above):

Barbara Kane, Plng Bd. And Code Enf. Officer James Schoenmann

Known problems with flood maps for your community

Do you have specific areas that don't flood (1\% chance) but are currently in the floodplain?

Yes. Panels 3 and 6, wood Pond, Zone A with BAD of 1163; f.p. boundary elevation is $10^{\prime}$ and higher. Panels 3,4, and 5, Moose River (have LOMA data) connector to Long Pond (panel 5 and 8) BAD/BFE=1161'.

Do you have specific areas that flood (1\% chance) but are not mapped in the floodplain?

The town will notify us if they have any areas of concern on their submittal.

Note any significant changes in hydraulic structures (bridges, culverts, dams)

Yes. Rt. 201 bridge over Moose River in village center and approaches just

replaced by MDOT. Rd/bridge location shifted. Bridge elevation the same, maybe a bit wider. May not affect 100 year flows; contact MDOT.

Do you have (or are you proposing) high-development areas where you need new or restudied flood elevations or improved map scale?

See town's submittal.

\section{Community Resources}

Do you have aerial photography (or plans for any) (flight date, scale, color/bw)?

No, but there is someone local who can do it; town may consider cost sharing.

Do you have any topographic data (or plans for collecting) (digital terrain, contour maps)?

Yes. L'contour data available on wood Pond due to sewer project in 1984.

Do you have any data related to hydrologic/hydraulic studies (or plans for such studies)? No

Do you have dedicated GIS capabilities (if so, provide contact information)?

No

\section{Notes}

Woodard and Curran has l'topo data on wood Pond on disc that town will provide. Town also has some spot elevations associated with permitting projects that they can share. Also participated in call: Ella Frawley Plng. Bd.; Marilyn Chalker 
Scoping interview data for: New Portland, Town of

CID: 230365 Council Govt: Annual Town Meeting Date:

Town Govt:

Community Representative Interviewed

Robert A. Dunphy

Code Enforcement officer

Email: rdunphy@tdstelme.net Tel: (207) 628-4441Fax:

Floodplain Management Community Contact (if different from above):

Known problems with flood maps for your community

Do you have specific areas that don't flood (1\% chance) but are currently in the floodplain? No

Do you have specific areas that flood ( $1 \%$ chance) but are not mapped in the floodplain? No

Note any significant changes in hydraulic structures (bridges, culverts, dams)

Dam on Gilman Pond has hole and the gates do not work properly (they are manual)

Do you have (or are you proposing) high-development areas where you need new or restudied flood elevations or improved map scale?

Only around Gilman Pond

\section{Community Resources}

Do you have aerial photography (or plans for any) (flight date, scale, color/bw)?

OGIS

Do you have any topographic data (or plans for collecting) (digital terrain, contour maps)? OGIS

Do you have any data related to hydrologic/hydraulic studies (or plans for such studies)? No

Do you have dedicated GIS capabilities (if so, provide contact information)?

Yes

Notes

old maps - need to be updated 
SCOPING INTERVIEW Data for: New Portland, Town of

CID: 230365 Council Govt: Annual Town Meeting Date:

Town Govt:

Community Representative Interviewed

Andrea Reichert

Town Manager

Email:

Tel: (207) 628-4441Fax: (207) 628-4440

Floodplain Management Community Contact (if different from above):

Known problems with flood maps for your community

Do you have specific areas that don't flood (1\% chance) but are currently in the floodplain? No

Do you have specific areas that flood ( $1 \%$ chance) but are not mapped in the floodplain? No

Note any significant changes in hydraulic structures (bridges, culverts, dams)

Since the last mapping a dam was removed on Lemon Stream and on the Carrabassett River

Do you have (or are you proposing) high-development areas where you need new or restudied flood elevations or improved map scale?

A subdivision on the Carrabassett River with zone "A" designation - lots are not able to be sold without having developer or buyer have a professional determine the flood elevation

Community Resources

Do you have aerial photography (or plans for any) (flight date, scale, color/bw)?

No

Do you have any topographic data (or plans for collecting) (digital terrain, contour maps)? No

Do you have any data related to hydrologic/hydraulic studies (or plans for such studies)? No

Do you have dedicated GIS capabilities (if so, provide contact information)? No

\section{Notes}

There are several zone "A" designations with no Base Flood Elevations, such as Gilman Pond, Gilman Stream, Lemon Stream, and the entire length of the Carrabassett River that need the flood elevations to be determined.

Current maps are out dated and grossly inaccurate. There are several incorrect road names. 
SCOPING INTERVIEW DATA FOR: Nor ridgewOck, Town of

CID: 230178 Council Govt: Annual Town Meeting Date:

Town Govt: $\quad$ March

Community Representative Interviewed

Robert A. Dunphy

Code Enforcement Officer

Email: rdunphy@tdstelme.net

Tel: (207) 634-2252Fax: (207) 634-5285

Floodplain Management Community Contact (if different from above):

Known problems with flood maps for your community

Do you have specific areas that don't flood (1\% chance) but are currently in the floodplain? No

Do you have specific areas that flood ( $1 \%$ chance) but are not mapped in the floodplain? No

Note any significant changes in hydraulic structures (bridges, culverts, dams)

The dam on the sandy $\mathrm{R}$. is being removed; this area should be looked at. This affects the Sandy R. in Norridgewock \& Starks and the Kennebec Watershed

Do you have (or are you proposing) high-development areas where you need new or restudied flood elevations or improved map scale?

No

Community Resources

Do you have aerial photography (or plans for any) (flight date, scale, color/bw)? OGIS

Do you have any topographic data (or plans for collecting) (digital terrain, contour maps)? OGIS

Do you have any data related to hydrologic/hydraulic studies (or plans for such studies)? No

Do you have dedicated GIS capabilities (if so, provide contact information)? Yes

Notes

The FIRM maps/i.e. Flood Insurance Study profiles should be updated 
SCOPING INTERVIEW DATA FOR: Palmyra, Town of

CID: 230366 Council Govt: Annual Town Meeting Date:

Town Govt:

Community Representative Interviewed

Stephen W. Gould

not a representative

Email:

Tel:

Fax:

Floodplain Management Community Contact (if different from above):

Known problems with flood maps for your community

Do you have specific areas that don't flood ( $1 \%$ chance) but are currently in the floodplain? No

Do you have specific areas that flood ( $1 \%$ chance) but are not mapped in the floodplain? No

Note any significant changes in hydraulic structures (bridges, culverts, dams)

No

Do you have (or are you proposing) high-development areas where you need new or restudied flood elevations or improved map scale?

Yes. Sebasticook River; no BFE, high development area

Community Resources

Do you have aerial photography (or plans for any) (flight date, scale, color/bw)?

No

Do you have any topographic data (or plans for collecting) (digital terrain, contour maps)? No

Do you have any data related to hydrologic/hydraulic studies (or plans for such studies)? No

Do you have dedicated GIS capabilities (if so, provide contact information)? No

Notes 
SCOPING InTERVIeW Data for: Pittsfield, Town of

CID: 230127 Council Govt: Annual Town Meeting Date:

Town Govt:

Community Representative Interviewed

Marie S. Lougee

Surveyor

Email:

Tel: (207) 683-5000Fax:

(207) 683-5401

Floodplain Management Community Contact (if different from above):

Known problems with flood maps for your community

Do you have specific areas that don't flood (1\% chance) but are currently in the floodplain?

See Panel 5 of 15 and see panel 10 of 15 .

Do you have specific areas that flood ( $1 \%$ chance) but are not mapped in the floodplain? No

Note any significant changes in hydraulic structures (bridges, culverts, dams)

No

Do you have (or are you proposing) high-development areas where you need new or restudied flood elevations or improved map scale?

No

\section{Community Resources}

Do you have aerial photography (or plans for any) (flight date, scale, color/bw)?

No

Do you have any topographic data (or plans for collecting) (digital terrain, contour maps)? No

Do you have any data related to hydrologic/hydraulic studies (or plans for such studies)? No

Do you have dedicated GIS capabilities (if so, provide contact information)? No

Notes

Didn't feel comfortable talking to the other study just the parts identified.

They have a new CEO who was not here. 
SCOPING INTERVIEW DATA FOR: Skowhegan, Town of

CID: 230128 Council Govt: Annual Town Meeting Date:

Town Govt:

Community Representative Interviewed

Randall Gray

Code Enforcement Officer

Email: skowcode@skowhegan.org

Tel: (207) 474-6904Fax:

(207) 474-9413

Floodplain Management Community Contact (if different from above):

Known problems with flood maps for your community

Do you have specific areas that don't flood (1\% chance) but are currently in the floodplain?

Please see summary for Skowhegan (i.e. SPO comments)

Do you have specific areas that flood ( $1 \%$ chance) but are not mapped in the floodplain? No

Note any significant changes in hydraulic structures (bridges, culverts, dams)

No

Do you have (or are you proposing) high-development areas where you need new or restudied flood elevations or improved map scale?

No

\section{Community Resources}

Do you have aerial photography (or plans for any) (flight date, scale, color/bw)?

Yes. Various dates.

Do you have any topographic data (or plans for collecting) (digital terrain, contour maps)?

Yes. MDOT 3' contours, building footprints - data stored with Maine Department of Transportation and covers all of downtown

Do you have any data related to hydrologic/hydraulic studies (or plans for such studies)? Yes. Limited restudy for "New Balance" warehouse; No LOMR, New Balance Risk Management people also have data

Do you have dedicated GIS capabilities (if so, provide contact information)?

Yes. Jeff Hewett, Economic Development Director and GIS Person, 474-6905

Notes 
SCOPING INTERVIEW DATA FOR: Smithfield, Town of

CID: 230370 Council Govt: Annual Town Meeting Date:

Town Govt:

Community Representative Interviewed

Kenneth A. Hogate

Code Enforcement officer

Email: bhogate@panax.com

Tel: (207) 474-8865Fax:

Floodplain Management Community Contact (if different from above):

Known problems with flood maps for your community

Do you have specific areas that don't flood (1\% chance) but are currently in the floodplain? No

Do you have specific areas that flood (1\% chance) but are not mapped in the floodplain?

Yes. North Pond and East Pond could have areas not shown as floodprone.

Note any significant changes in hydraulic structures (bridges, culverts, dams)

No

Do you have (or are you proposing) high-development areas where you need new or restudied flood elevations or improved map scale?

Yes. All area around ponds are under high develop

\section{Community Resources}

Do you have aerial photography (or plans for any) (flight date, scale, color/bw)?

No

Do you have any topographic data (or plans for collecting) (digital terrain, contour maps)? No

Do you have any data related to hydrologic/hydraulic studies (or plans for such studies)? No

Do you have dedicated GIS capabilities (if so, provide contact information)? No

Notes

First priority is East Pond; has most development. Second priority is North Pond, boundaries need better definition. 
SCOPING INTERVIEW DATA FOR: Solon, Town of

CID: 230371 Council Govt: Annual Town Meeting Date:

Town Govt: $\quad$ 1st Saturday of March

Community Representative Interviewed

Michael R. Sackett

Planning Board

Email: msackett@sackettandbrake.com

Tel: (207) 474-6223Fax:

(207) 474-6223

Floodplain Management Community Contact (if different from above):

Unsure

Known problems with flood maps for your community

Do you have specific areas that don't flood (1\% chance) but are currently in the floodplain?

Yes. Ironbound Pond and Fall Brook. See map marked up

Do you have specific areas that flood ( $1 \%$ chance) but are not mapped in the floodplain? No

Note any significant changes in hydraulic structures (bridges, culverts, dams)

Yes. Larger culverts River Road

Do you have (or are you proposing) high-development areas where you need new or restudied flood elevations or improved map scale?

No

\section{Community Resources}

Do you have aerial photography (or plans for any) (flight date, scale, color/bw)?

Yes. 1999, in color. Good enough for 4' contours; may be too many leaves (fall).

Do you have any topographic data (or plans for collecting) (digital terrain, contour maps)? No

Do you have any data related to hydrologic/hydraulic studies (or plans for such studies)? No

Do you have dedicated GIS capabilities (if so, provide contact information)?

Yes. Mary-Lou Ridley; Second select-person. Contact town office.

Notes

Need 100000010333; Not an issue (Kennebec River). Wentworth Pond (A.K.A. Ironbound Pond) valid but decrease instead of increase. 
SCOPING INTERVIEW DATA FOR:

CID: 0
Council Govt:

Town Govt:

\section{Somerset County}

Annual Town Meeting Date:

Community Representative Interviewed

Robert F. Niggins Sr.

Director - Somerset County EMA

Email:

Tel: (207) 474-6788Fax:

Floodplain Management Community Contact (if different from above):

Known problems with flood maps for your community

Do you have specific areas that don't flood (1\% chance) but are currently in the floodplain? No

Do you have specific areas that flood ( $1 \%$ chance) but are not mapped in the floodplain? No

Note any significant changes in hydraulic structures (bridges, culverts, dams) No

Do you have (or are you proposing) high-development areas where you need new or restudied flood elevations or improved map scale?

Proposed areas of development in Somerset County; Plum Creek Proposal, Lake Moxie Development Area; both are LURC jurisdiction

\section{Community Resources}

Do you have aerial photography (or plans for any) (flight date, scale, color/bw)? No

Do you have any topographic data (or plans for collecting) (digital terrain, contour maps)? No

Do you have any data related to hydrologic/hydraulic studies (or plans for such studies)? No

Do you have dedicated GIS capabilities (if so, provide contact information)? No

Notes 
SCOPING INTERVIEW DATA FOR: St. Albans, Town of

CID: 230369 Council Govt: Annual Town Meeting Date:

Town Govt:

Community Representative Interviewed

Stephen W., Marie, and Onie

Not representatives of town

Email:

Tel:

Fax:

Floodplain Management Community Contact (if different from above):

William Murphy

Known problems with flood maps for your community

Do you have specific areas that don't flood (1\% chance) but are currently in the floodplain?

Yes. Numerous; highlighted on maps

Do you have specific areas that flood ( $1 \%$ chance) but are not mapped in the floodplain? No

Note any significant changes in hydraulic structures (bridges, culverts, dams)

No

Do you have (or are you proposing) high-development areas where you need new or restudied flood elevations or improved map scale?

Yes. Indian Pond (Little and Big), several streams on all maps. Snell Brook

needs a BFE. Smalls streams southern portion town in higher development areas.

\section{Community Resources}

Do you have aerial photography (or plans for any) (flight date, scale, color/bw)?

No

Do you have any topographic data (or plans for collecting) (digital terrain, contour maps)? No

Do you have any data related to hydrologic/hydraulic studies (or plans for such studies)? No

Do you have dedicated GIS capabilities (if so, provide contact information)? No

Notes 
SCOPING INTERVIEW DATA FOR: Starks, TOWn of

CID: 230372 Council Govt: Annual Town Meeting Date:

Town Govt: $\quad$ March

Community Representative Interviewed

David Hartigan

CEO/LPI

Email:

Tel: (207) 696-3919Fax:

Floodplain Management Community Contact (if different from above):

Known problems with flood maps for your community

Do you have specific areas that don't flood (1\% chance) but are currently in the floodplain? No

Do you have specific areas that flood ( $1 \%$ chance) but are not mapped in the floodplain? No

Note any significant changes in hydraulic structures (bridges, culverts, dams)

No

Do you have (or are you proposing) high-development areas where you need new or restudied flood elevations or improved map scale?

No

Community Resources

Do you have aerial photography (or plans for any) (flight date, scale, color/bw)?

Yes; 30 year old aerial photos from USGS

Do you have any topographic data (or plans for collecting) (digital terrain, contour maps)?

Yes. Every fall I take one, sometimes two flights over and around the town. Each flight is about one hour long.

Do you have any data related to hydrologic/hydraulic studies (or plans for such studies)? No

Do you have dedicated GIS capabilities (if so, provide contact information)? No

Notes 
Appendix D: Existing MNUSS Data Entries: Somerset County 


\section{BINGHAM, TOWN OF}

MNUSS NeedID 100000000010193

AUSTIN CREEK

Need Desc: Changes to hydrologic conditions
CID 230124 MNUSS Summary

Date of Need: 9/17/1997

Panel: 230124 B

Length: $\odot .32 \mathrm{mi}$

Anticipated BFE Change: Increased By Greater Than 5 feet

Location of Floodplain:

Need Notes: THIS IS AN 11X17 AND WILL HAVE TO BE FORMATTED TO A Z-FOLD

SPO Comments: Restudy in process

MNUSS NeedID 100000000010372

Date of Need: 6/8/1999

KENNEBEC RIVER

Need Desc: Changes to hydrologic conditions

Panel: 230124 B

Length: $7.06 \mathrm{mi}$

Anticipated BFE Change: Increased By Greater Than 5 feet

Location of Floodplain:

Need Notes:

SPO Comments: Restudy in process 


\section{BINGHAM, TOWN OF}

MNUSS NeedID 100000000035196

AUSTIN CREEK

Need Desc: Changes to BFEs
CID 230124 MNUSS Summary

Date of Need: 6/16/2004

Panel:

Length: 10 mi

Anticipated BFE Change: Increased By Between 1 and 5 feet

Location of Floodplain: All of Austin Stream has a detailed study performed by the NRCS and the NRCS study should be incorporated into the USGS FIS restudy now in draft form (April 2004 or earlier).

Need Notes: Sue determined from NRCS that a detailed study exists for Austin Brook \& would like it incorporated into the community restudy done by USGS and in draft form as of April 2004.

SPO Comments: Restudy in process

MNUSS NeedID 100000000035196

AUSTIN CREEK

Need Desc: Changes to floodplain width
Date of Need: $6 / 16 / 2004$

Panel:

Length: 10 mi

Anticipated BFE Change: Increased By Between 1 and 5 feet

Location of Floodplain: All of Austin Stream has a detailed study performed by the NRCS and the NRCS study should be incorporated into the USGS FIS restudy now in draft form (April 2004 or earlier).

Need Notes: Sue determined from NRCS that a detailed study exists for Austin Brook \& would like it incorporated into the community restudy done by USGS and in draft form as of April 2004.

SPO Comments: Restudy in process 


\section{BINGHAM, TOWN OF}

MNUSS NeedID 100000000035196

AUSTIN CREEK

Need Desc: Changes to hydraulic analysis
CID 230124 MNUSS Summary

Date of Need: 6/16/2004

Panel:

Length: $10 \quad$ mi

Anticipated BFE Change: Increased By Between 1 and 5 feet

Location of Floodplain: All of Austin Stream has a detailed study performed by the NRCS and the NRCS study should be incorporated into the USGS FIS restudy now in draft form (April 2004 or earlier).

Need Notes: Sue determined from NRCS that a detailed study exists for Austin Brook \& would like it incorporated into the community restudy done by USGS and in draft form as of April 2004.

SPO Comments: Restudy in process

MNUSS NeedID 100000000035196

AUSTIN CREEK

Need Desc: Changes to hydrologic conditions
Date of Need: 6/16/2004

Panel:

Length: 10 mi

Anticipated BFE Change: Increased By Between 1 and 5 feet

Location of Floodplain: All of Austin Stream has a detailed study performed by the NRCS and the NRCS study should be incorporated into the USGS FIS restudy now in draft form (April 2004 or earlier).

Need Notes: Sue determined from NRCS that a detailed study exists for Austin Brook \& would like it incorporated into the community restudy done by USGS and in draft form as of April 2004.

SPO Comments: Restudy in process 


\section{CANAAN, TOWN OF}

MNUSS NeedID 100000000025937

Sibley Pond

Need Desc: Changes to hydrologic conditions
CID 230356 MNUSS Summary

Date of Need: 9/26/2001

Panel: 230356 B

Length: $2.1 \mathrm{mi}$

Anticipated BFE Change: Increased By Greater Than 5 feet

Location of Floodplain:

Need Notes:

SPO Comments: See SPO B.A.D.

MNUSS NeedID 100000000010200

Date of Need: 9/25/1997

Panel: 230357 A

Need Desc: Add streets to panel

Length: $\odot \quad$ mi

Anticipated BFE Change: Not Applicable

Location of Floodplain:

Need Notes:

SPO Comments: DFIRM process will address 
EXISTING MNUSS ENTRIES FOR SOMERSET COUNTY

\section{HARMONY, TOWN OF}

MNUSS NeedID 100000000025864

Need Desc: Add streets to panel
CID 230360 MNUSS Summary

Date of Need: $8 / 29 / 2001$

Panel: 230360 B

Length: $\odot \quad$ mi

\footnotetext{
Anticipated BFE Change: Not Applicable

Location of Floodplain:

Need Notes: South Road is not located correctly near Higgins Brook.

SPO Comments: DFIRM process will address
} 
EXISTING MNUSS ENTRIES FOR SOMERSET COUNTY

\section{MADISON, TOWN OF}

MNUSS NeedID 100000000010354

KENNEBEC RIVER

Need Desc: Changes to floodplain width
CID 230126 MNUSS Summary

Date of Need: 3/24/1998

Panel: $2301260002 \mathrm{C}$

Length: $11.42 \quad \mathrm{mi}$

Anticipated BFE Change: Increased By Greater Than 5 feet

Location of Floodplain:

Need Notes: Mill dam in community has been improved, backing up the reservoir to a higher elevation.

SPO Comments: New flashboards - impact bfe ??

MNUSS NeedID 100000000010354

Date of Need: 3/24/1998

KENNEBEC RIVER

Panel: $2301260004 \mathrm{C}$

Need Desc: Changes to floodplain width

Length: 11.42

mi

Anticipated BFE Change: Increased By Greater Than 5 feet

Location of Floodplain:

Need Notes: Mill dam in community has been improved, backing up the reservoir to a higher elevation.

SPO Comments: New flashboards - impact bfe ?? 
EXISTING MNUSS ENTRIES FOR SOMERSET COUNTY

\section{MADISON, TOWN OF}

MNUSS NeedID 100000000010354

KENNEBEC RIVER

Need Desc: Changes to floodplain width
CID 230126 MNUSS Summary

Date of Need: 3/24/1998

Panel: $2301260012 \mathrm{C}$

Length: 11.42 mi

Anticipated BFE Change: Increased By Greater Than 5 feet

Location of Floodplain:

Need Notes: Mill dam in community has been improved, backing up the reservoir to a higher elevation.

SPO Comments: New flashboards - impact bfe ??

MNUSS NeedID 100000000010354

Date of Need: 3/24/1998

KENNEBEC RIVER

Panel: $2301260014 \mathrm{C}$

Need Desc: Changes to floodplain width

Length: 11.42 mi

Anticipated BFE Change: Increased By Greater Than 5 feet

Location of Floodplain:

Need Notes: Mill dam in community has been improved, backing up the reservoir to a higher elevation.

SPO Comments: New flashboards - impact bfe ?? 


\section{MOSCOW, TOWN OF}

MNUSS NeedID 100000000035197

Austin Stream

Need Desc: Changes to floodplain width
CID 230364 MNUSS Summary

Date of Need: 6/16/2004

Panel:

Length: $10 \quad$ mi

Anticipated BFE Change: Increased By Between 1 and 5 feet

Location of Floodplain: Add existing detailed study for Austin Brook avail from an NRCS study.

Need Notes: In a 4/04 contact with the FEMA region I office, sue noted the availability of an existing detailed study for Austin Brook by NRCS and would like the data incorporated into the town's FIS.

SPO Comments: Valid

MNUSS NeedID 100000000035197

Austin Stream

Need Desc: Changes to hydraulic analysis
Date of Need: 6/16/2004

Panel:

Length: 10 mi

Anticipated BFE Change: Increased By Between 1 and 5 feet

Location of Floodplain: Add existing detailed study for Austin Brook avail from an NRCS study.

Need Notes: In a 4/04 contact with the FEMA region I office, sue noted the availability of an existing detailed study for Austin Brook by NRCS and would like the data incorporated into the town's FIS.

SPO Comments: Valid 


\section{MOSCOW, TOWN OF}

MNUSS NeedID 100000000035197

Austin Stream

Need Desc: Changes to BFEs
CID 230364 MNUSS Summary

Date of Need: $6 / 16 / 2004$

Panel:

Length: $10 \quad \mathrm{mi}$

Anticipated BFE Change: Increased By Between 1 and 5 feet

Location of Floodplain: Add existing detailed study for Austin Brook avail from an NRCS study.

Need Notes: In a 4/04 contact with the FEMA region I office, sue noted the availability of an existing detailed study for Austin Brook by NRCS and would like the data incorporated into the town's FIS.

SPO Comments: Valid

MNUSS NeedID 100000000035197

Austin Stream

Need Desc: Changes to hydrologic conditions
Date of Need: 6/16/2004

Panel:

Length: 10 mi

Anticipated BFE Change: Increased By Between 1 and 5 feet

Location of Floodplain: Add existing detailed study for Austin Brook avail from an NRCS study.

Need Notes: In a 4/O4 contact with the FEMA region I office, sue noted the availability of an existing detailed study for Austin Brook by NRCS and would like the data incorporated into the town's FIS.

SPO Comments: Valid 
EXISTING MNUSS ENTRIES FOR SOMERSET COUNTY

SKOWHEGAN, TOWN OF

MNUSS NeedID 100000000030973

Several rivers in town

Need Desc: Changes to hydraulic analysis
CID 230128 MNUSS Summary

Date of Need: $3 / 25 / 2003$

Panel: $2301280010 \mathrm{C}$

Length: 25 mi

Anticipated BFE Change: Decreased By Between 1 and 5 feet

Location of Floodplain: corporate boundary to corporate boundary

Need Notes:

SPO Comments: Valid

MNUSS NeedID 100000000030973

Date of Need: $3 / 25 / 2003$

Several rivers in town

Panel: $2301280001 \mathrm{C}$

Need Desc: Changes to BFEs

Length: 25 mi

Anticipated BFE Change: Decreased By Between 1 and 5 feet

Location of Floodplain: corporate boundary to corporate boundary

Need Notes:

SPO Comments: Valid 


\section{SKOWHEGAN, TOWN OF}

MNUSS NeedID 100000000030973

Several rivers in town

Need Desc: Changes to BFEs
CID 230128 MNUSS Summary

Date of Need: $3 / 25 / 2003$

Panel: $2301280003 \mathrm{C}$

Length: 25 mi

Anticipated BFE Change: Decreased By Between 1 and 5 feet

Location of Floodplain: corporate boundary to corporate boundary

Need Notes:

SPO Comments: Valid

MNUSS NeedID 100000000030973

Date of Need: $3 / 25 / 2003$

Several rivers in town

Panel: $2301280010 \mathrm{C}$

Need Desc: Changes to BFEs

Length: 25 mi

Anticipated BFE Change: Decreased By Between 1 and 5 feet

Location of Floodplain: corporate boundary to corporate boundary

Need Notes:

SPO Comments: Valid 
EXISTING MNUSS ENTRIES FOR SOMERSET COUNTY

\section{SKOWHEGAN, TOWN OF}

MNUSS NeedID 100000000030973

Several rivers in town

Need Desc: Changes to hydraulic analysis
CID 230128 MNUSS Summary

Date of Need: 3/25/2003

Panel: $2301280001 \mathrm{C}$

Length: 25 mi

Anticipated BFE Change: Decreased By Between 1 and 5 feet

Location of Floodplain: corporate boundary to corporate boundary

Need Notes:

SPO Comments: Valid

MNUSS NeedID 100000000030973

Date of Need: $3 / 25 / 2003$

Several rivers in town

Need Desc: Changes to hydraulic analysis

Panel: $2301280003 \mathrm{C}$

Length: 25 mi

Anticipated BFE Change: Decreased By Between 1 and 5 feet

Location of Floodplain: corporate boundary to corporate boundary

Need Notes:

SPO Comments: Valid 


\section{SKOWHEGAN, TOWN OF}

MNUSS NeedID 100000000031135

\section{Cold Brook}

Need Desc: No Changes to BFEs
CID 230128 MNUSS Summary

Date of Need: 6/6/2003

Panel: $2301280002 \mathrm{C}$

Length: 5 mi

Anticipated BFE Change: Increased By Less Than 1 foot

Location of Floodplain: entire length of stream

Need Notes: fEB. 26, 2003 FOLLOW-UP LETTER BY STATE TO jAN. 21, 2003 cav INDICATES THAT FLOODPLAIN BOUNDARIES for Cold Brook do not fit the existing topography

SPO Comments: Valid

MNUSS NeedID 100000000031135

Cold Brook

Need Desc: No Changes to BFEs
Date of Need: 6/6/2003

Panel: $2301280001 \mathrm{C}$

Length: 5 mi

Anticipated BFE Change: Increased By Less Than 1 foot

Location of Floodplain: entire length of stream

Need Notes: fEB. 26, 2003 FOLLOW-UP LETTER BY STATE TO jAN. 21, 2003 cav INDICATES THAT FLOODPLAIN BOUNDARIES for Cold Brook do not fit the existing topography

SPO Comments: Valid 


\section{SKOWHEGAN, TOWN OF}

MNUSS NeedID 100000000031135

\section{Cold Brook}

Need Desc: Changes to floodplain width
CID 230128 MNUSS Summary

Date of Need: 6/6/2003

Panel: $2301280001 \mathrm{C}$

Length: 5 mi

Anticipated BFE Change: Increased By Less Than 1 foot

Location of Floodplain: entire length of stream

Need Notes: fEB. 26, 2003 FOLLOW-UP LETTER BY STATE TO jAN. 21, 2003 cav INDICATES THAT FLOODPLAIN BOUNDARIES for Cold Brook do not fit the existing topography

SPO Comments: Valid

MNUSS NeedID 100000000031135

\section{Cold Brook}

Need Desc: Changes to floodplain width
Date of Need: 6/6/2003

Panel: $2301280002 \mathrm{C}$

Length: 5 mi

Anticipated BFE Change: Increased By Less Than 1 foot

Location of Floodplain: entire length of stream

Need Notes: fEB. 26, 2003 FOLLOW-UP LETTER BY STATE TO jAN. 21, 2003 cav INDICATES THAT FLOODPLAIN BOUNDARIES for Cold Brook do not fit the existing topography

SPO Comments: Valid 
SKOWHEGAN, TOWN OF

MNUSS NeedID 100000000031136

KENNEBEC RIVER

Need Desc: No Changes to BFEs
CID 230128 MNUSS Summary

Date of Need: 6/6/2003

Panel: $2301280003 \mathrm{C}$

Length: 1 mi

Anticipated BFE Change: Increased By Between 1 and 5 feet

Location of Floodplain: area surrounding the intersection of pleasant street and Madison Ave.

Need Notes: Additionally, on panel 4, in the area between East Front Street and Hathaway street, the horizontal control appears to be off by more than 60 feet (as noted in 2/26/2003 follow-up letter to $1 / 26 / 03 \mathrm{CAV})$. CAV follow-up letter notes that community has raised this concern with FEMA before (2/99).

SPO Comments: Valid

MNUSS NeedID 100000000031136

KENNEBEC RIVER

Need Desc: Changes to floodplain width
Date of Need: 6/6/2003

Panel: $2301280003 \mathrm{C}$

Length: 1 mi

Anticipated BFE Change: Increased By Between 1 and 5 feet

Location of Floodplain: area surrounding the intersection of pleasant street and Madison Ave.

Need Notes: In 2/26/2003 follow-up letter to $1 / 26 / 2003$ CAV by state, town indicates that the area of concern (see limits) is currently mapped on the FIRM as a shaded Zone $X$. The area is below the BFE of $173 \mathrm{ft}$ NGVD which is documented with manhole rim elevations and historical flooding events.

SPO Comments: Valid 
SKOWHEGAN, TOWN OF

MNUSS NeedID 100000000031136

KENNEBEC RIVER

Need Desc: Changes to floodplain width
CID 230128 MNUSS Summary

Date of Need: 6/6/2003

Panel: $2301280003 \mathrm{C}$

Length: 1 mi

Anticipated BFE Change: Increased By Between 1 and 5 feet

Location of Floodplain: area surrounding the intersection of pleasant street and Madison Ave.

Need Notes: Additionally, on panel 4, in the area between East Front Street and Hathaway Street, the horizontal control appears to be off by more than 60 feet (as noted in 2/26/2003 follow-up letter to $1 / 26 / 03 \mathrm{CAV})$. CAV follow-up letter notes that community has raised this concern with FEMA before (2/99).

SPO Comments: Valid

MNUSS NeedID 100000000031136

KENNEBEC RIVER

Need Desc: Changes to floodplain width
Date of Need: 6/6/2003

Panel: $2301280004 \mathrm{C}$

Length: 1 mi

Anticipated BFE Change: Increased By Between 1 and 5 feet

Location of Floodplain: area surrounding the intersection of pleasant street and Madison Ave.

Need Notes: In 2/26/2003 follow-up letter to 1/26/2003 CAV by state, town indicates that the area of concern (see limits) is currently mapped on the FIRM as a shaded Zone $X$. The area is below the BFE of $173 \mathrm{ft}$ NGVD which is documented with manhole rim elevations and historical flooding events.

SPO Comments: Valid 
SKOWHEGAN, TOWN OF

MNUSS NeedID 100000000031136

KENNEBEC RIVER

Need Desc: Changes to floodplain width
CID 230128 MNUSS Summary

Date of Need: 6/6/2003

Panel: $2301280004 \mathrm{C}$

Length: 1 mi

Anticipated BFE Change: Increased By Between 1 and 5 feet

Location of Floodplain: area surrounding the intersection of pleasant street and Madison Ave.

Need Notes: Additionally, on panel 4, in the area between East Front Street and Hathaway Street, the horizontal control appears to be off by more than 60 feet (as noted in 2/26/2003 follow-up letter to $1 / 26 / 03 \mathrm{CAV})$. CAV follow-up letter notes that community has raised this concern with FEMA before (2/99).

SPO Comments: Valid

MNUSS NeedID 100000000031136

KENNEBEC RIVER

Need Desc: No Changes to BFEs
Date of Need: 6/6/2003

Panel: $2301280004 \mathrm{C}$

Length: 1 mi

Anticipated BFE Change: Increased By Between 1 and 5 feet

Location of Floodplain: area surrounding the intersection of pleasant street and Madison Ave.

Need Notes: In 2/26/2003 follow-up letter to 1/26/2003 CAV by state, town indicates that the area of concern (see limits) is currently mapped on the FIRM as a shaded Zone $X$. The area is below the BFE of $173 \mathrm{ft}$ NGVD which is documented with manhole rim elevations and historical flooding events.

SPO Comments: Valid 
SKOWHEGAN, TOWN OF

MNUSS NeedID 100000000031136

KENNEBEC RIVER

Need Desc: No Changes to BFEs
CID 230128 MNUSS Summary

Date of Need: 6/6/2003

Panel: $2301280004 \mathrm{C}$

Length: 1 mi

Anticipated BFE Change: Increased By Between 1 and 5 feet

Location of Floodplain: area surrounding the intersection of pleasant street and Madison Ave.

Need Notes: Additionally, on panel 4, in the area between East Front Street and Hathaway street, the horizontal control appears to be off by more than 60 feet (as noted in 2/26/2003 follow-up letter to $1 / 26 / 03 \mathrm{CAV})$. CAV follow-up letter notes that community has raised this concern with FEMA before (2/99).

SPO Comments: Valid

MNUSS NeedID 100000000031136

KENNEBEC RIVER

Need Desc: No Changes to BFEs
Date of Need: 6/6/2003

Panel: $2301280003 \mathrm{C}$

Length: 1 mi

Anticipated BFE Change: Increased By Between 1 and 5 feet

Location of Floodplain: area surrounding the intersection of pleasant street and Madison Ave.

Need Notes: In 2/26/2003 follow-up letter to 1/26/2003 CAV by state, town indicates that the area of concern (see limits) is currently mapped on the FIRM as a shaded Zone $X$. The area is below the BFE of $173 \mathrm{ft}$ NGVD which is documented with manhole rim elevations and historical flooding events.

SPO Comments: Valid 


\section{SMITHFIELD, TOWN OF}

MNUSS NeedID 100000000010122

North Pond

Need Desc: Changes to BFEs
CID 230370 MNUSS Summary

Date of Need: 8/4/1997

Panel: 230370 B

Length: $3.9 \mathrm{mi}$

Anticipated BFE Change: Increased By Between 1 and 5 feet

Location of Floodplain:

Need Notes: Add a BFE to North Pond based on Town of Mercer restudy. Should be processed as an XDS, no SC costs. Please note, community effective is $11 \times 17$ FIRM, panels affected include $4,8,10$.

SPO Comments: See SPO B.A.D.

MNUSS NeedID 100000000010122

Date of Need: 8/4/1997

North Pond

Panel: 230370 B

Need Desc: Changes to BFEs

Length: $3.9 \mathrm{mi}$

Anticipated BFE Change: Increased By Between 1 and 5 feet

Location of Floodplain:

Need Notes: Add a BFE to North Pond based on Town of Mercer restudy. Should be processed as an XDS, no SC costs. Please note, community effective is $11 \times 17$ FIRM, panels affected include 4,8,10.

SPO Comments: See SPO B.A.D. 


\section{SMITHFIELD, TOWN OF}

MNUSS NeedID 100000000010122

North Pond

Need Desc: Changes to BFEs
CID 230370 MNUSS Summary

Date of Need: 8/4/1997

Panel: 230370 B

Length: $3.9 \mathrm{mi}$

Anticipated BFE Change: Increased By Between 1 and 5 feet

Location of Floodplain:

Need Notes: Add a BFE to North Pond based on Town of Mercer restudy. Should

be processed as an XDS, no SC costs. Please note, community effective is $11 \times 17$ FIRM, panels affected include 4, 8, 10 .

SPO Comments: See SPO B.A.D.

MNUSS NeedID 100000000010163

Need Desc: Add streets to panel

Anticipated BFE Change: Not Applicable

Location of Floodplain:

Need Notes:

SPO Comments: DFIRM process will address
Date of Need: 8/4/1997

Panel: 230370 B

Length: $\odot \quad$ mi 
EXISTING MNUSS ENTRIES FOR SOMERSET COUNTY

\section{SOLON, TOWN OF}

MNUSS NeedID 100000000010333

KENNEBEC RIVER

Need Desc: Changes to hydraulic analysis
CID 230371 MNUSS Summary

Date of Need: 12/29/1997

Panel: 230371 B

Length: $3.54 \mathrm{mi}$

Anticipated BFE Change: Increased By Greater Than 5 feet

Location of Floodplain:

Need Notes: INCREASED DEVELOPMENT VALIDATES RESTUDY

SPO Comments: Data upstream and downstream?

MNUSS NeedID 100000000010333

Date of Need: 12/29/1997

KENNEBEC RIVER

Need Desc: Changes to hydraulic analysis

Panel: 230371 B

Length: $3.54 \mathrm{mi}$

Anticipated BFE Change: Increased By Greater Than 5 feet

Location of Floodplain:

Need Notes: INCREASED DEVELOPMENT VALIDATES RESTUDY

SPO Comments: Data upstream and downstream? 
EXISTING MNUSS ENTRIES FOR SOMERSET COUNTY

\section{SOLON, TOWN OF}

MNUSS NeedID 100000000010332

WENTWORTH POND

Need Desc: Changes to floodplain width
CID 230371 MNUSS Summary

Date of Need: 12/29/1997

Panel: 230371 B

Length: $2.63 \mathrm{mi}$

Anticipated BFE Change: Increased By Greater Than 5 feet

Location of Floodplain:

Need Notes:

SPO Comments: Valid 


\section{ST. ALBANS, TOWN OF}

MNUSS NeedID 100000000010176

RAY BROOK

Need Desc: Changes to BFEs
CID 230369 MNUSS Summary

Date of Need: 9/17/1997

Panel: 230369 A

Length: $2.7 \mathrm{mi}$

Anticipated BFE Change: Increased By Greater Than 5 feet

Location of Floodplain:

Need Notes: THIS IS AN 11X17 AND WILL HAVE TO BE FORMATTED TO A Z-FOLD

SPO Comments: See SPO B.A.D.

MNUSS NeedID 100000000010178

Date of Need: 9/17/1997

MULLIGIN STREAM

Panel: 230369 A

Need Desc: Changes to BFEs

Length: $1.8 \mathrm{mi}$

Anticipated BFE Change: Increased By Greater Than 5 feet

Location of Floodplain:

Need Notes: THIS IS AN 11X17 AND WILL HAVE TO BE FORMATTED TO A Z-FOLD.

SPO Comments: ? 


\section{ST. ALBANS, TOWN OF}

MNUSS NeedID 100000000010180

GOODWIN BROOK

Need Desc: Changes to BFEs
CID 230369 MNUSS Summary

Date of Need: 9/17/1997

Panel: 230369 A

Length: $3.6 \mathrm{mi}$

Anticipated BFE Change: Increased By Greater Than 5 feet

Location of Floodplain:

Need Notes: THIS IS AN 11X17 AND WILL HAVE TO BE FORMATTED TO A Z-FOLD.

SPO Comments: ?

MNUSS NeedID 100000000010180

Date of Need: 9/17/1997

\section{GOODWIN BROOK}

Need Desc: Changes to BFEs

Panel: 230369 A

Length: $3.6 \mathrm{mi}$

Anticipated BFE Change: Increased By Greater Than 5 feet

Location of Floodplain:

Need Notes: THIS IS AN 11X17 AND WILL HAVE TO BE FORMATTED TO A Z-FOLD.

SPO Comments: ? 


\section{ST. ALBANS, TOWN OF}

MNUSS NeedID 100000000010180

GOODWIN BROOK

Need Desc: Changes to BFEs
CID 230369 MNUSS Summary

Date of Need: 9/17/1997

Panel: 230369 A

Length: $3.6 \mathrm{mi}$

Anticipated BFE Change: Increased By Greater Than 5 feet

Location of Floodplain:

Need Notes: THIS IS AN 11X17 AND WILL HAVE TO BE FORMATTED TO A Z-FOLD.

SPO Comments: ?

MNUSS NeedID 100000000010179

Date of Need: $9 / 17 / 1997$

\section{HAMSON WHITE BROOK}

Panel: 230369 A

Need Desc: Changes to BFEs

Length: $2.2 \mathrm{mi}$

Anticipated BFE Change: Increased By Greater Than 5 feet

Location of Floodplain:

Need Notes: THIS IS AN 11X17 AND WILL HAVE TO BE FORMATTED TO A Z-FOLD.

SPO Comments: ? 


\section{ST. ALBANS, TOWN OF}

MNUSS NeedID 100000000010181

MELON BROOK

Need Desc: Changes to BFEs
CID 230369 MNUSS Summary

Date of Need: 9/17/1997

Panel: 230369 A

Length: $3.5 \mathrm{mi}$

Anticipated BFE Change: Increased By Greater Than 5 feet

Location of Floodplain:

Need Notes: THIS IS AN 11X17 AND WILL HAVE TO BE FORMATTED TO A Z-FOLD.

SPO Comments: See SPO B.A.D.

MNUSS NeedID 100000000010179

Date of Need: 9/17/1997

HARRISON WHITE BROOK

Panel: 230369 A

Need Desc: Changes to BFEs

Length: $2.2 \mathrm{mi}$

Anticipated BFE Change: Increased By Greater Than 5 feet

Location of Floodplain:

Need Notes: THIS IS AN 11X17 AND WILL HAVE TO BE FORMATTED TO A Z-FOLD.

SPO Comments: ? 


\section{ST. ALBANS, TOWN OF}

MNUSS NeedID 100000000010179

\section{HARRISON WHITE BROOK}

Need Desc: Changes to BFEs
CID 230369 MNUSS Summary

Date of Need: 9/17/1997

Panel: 230369 A

Length: $2.2 \mathrm{mi}$

Anticipated BFE Change: Increased By Greater Than 5 feet

Location of Floodplain:

Need Notes: THIS IS AN 11X17 AND WILL HAVE TO BE FORMATTED TO A Z-FOLD.

SPO Comments: ?

MNUSS NeedID 100000000010181

Date of Need: 9/17/1997

\section{MELON BROOK}

Need Desc: Changes to BFEs

Panel: 230369 A

Length: $3.5 \mathrm{mi}$

Anticipated BFE Change: Increased By Greater Than 5 feet

Location of Floodplain:

Need Notes: THIS IS AN 11X17 AND WILL HAVE TO BE FORMATTED TO A Z-FOLD.

SPO Comments: See SPO B.A.D. 


\section{ST. ALBANS, TOWN OF}

MNUSS NeedID 100000000010178

MULLIGIN STREAM

Need Desc: Changes to BFEs
CID 230369 MNUSS Summary

Date of Need: 9/17/1997

Panel: 230369 A

Length: $1.8 \mathrm{mi}$

Anticipated BFE Change: Increased By Greater Than 5 feet

Location of Floodplain:

Need Notes: THIS IS AN 11X17 AND WILL HAVE TO BE FORMATTED T0 A Z-FOLD.

SPO Comments: ?

MNUSS NeedID 100000000010178

Date of Need: 9/17/1997

MULLIGIN STREAM

Panel: 230369 A

Need Desc: Changes to BFEs

Length: $1.8 \mathrm{mi}$

Anticipated BFE Change: Increased By Greater Than 5 feet

Location of Floodplain:

Need Notes: THIS IS AN 11X17 AND WILL HAVE TO BE FORMATTED TO A Z-FOLD.

SPO Comments: ? 


\section{ST. ALBANS, TOWN OF}

MNUSS NeedID 100000000010177

INDIAN STREAM

Need Desc: Changes to BFEs
CID 230369 MNUSS Summary

Date of Need: 9/17/1997

Panel: 230369 A

Length: 3 mi

Anticipated BFE Change: Increased By Greater Than 5 feet

Location of Floodplain:

Need Notes: THIS IS AN 11X17 AND WILL HAVE TO BE FORMATTED TO A Z-FOLD.

SPO Comments: See SPO B.A.D.

MNUSS NeedID 100000000010177

Date of Need: 9/17/1997

\section{INDIAN STREAM}

Need Desc: Changes to BFEs

Panel: 230369 A

Length: 3 mi

Anticipated BFE Change: Increased By Greater Than 5 feet

Location of Floodplain:

Need Notes: THIS IS AN 11X17 AND WILL HAVE TO BE FORMATTED TO A Z-FOLD.

SPO Comments: See SPO B.A.D. 


\section{ST. ALBANS, TOWN OF}

MNUSS NeedID 100000000010176

RAY BROOK

Need Desc: Changes to BFEs
CID 230369 MNUSS Summary

Date of Need: 9/17/1997

Panel: 230369 A

Length: $2.7 \mathrm{mi}$

Anticipated BFE Change: Increased By Greater Than 5 feet

Location of Floodplain:

Need Notes: THIS IS AN 11X17 AND WILL HAVE TO BE FORMATTED TO A Z-FOLD

SPO Comments: See SPO B.A.D.

MNUSS NeedID 100000000010176

Date of Need: 9/17/1997

RAY BROOK

Panel: 230369 A

Need Desc: Changes to BFEs

Length: $2.7 \mathrm{mi}$

Anticipated BFE Change: Increased By Greater Than 5 feet

Location of Floodplain:

Need Notes: THIS IS AN 11X17 AND WILL HAVE TO BE FORMATTED TO A Z-FOLD

SPO Comments: See SPO B.A.D. 
EXISTING MNUSS ENTRIES FOR SOMERSET COUNTY

\section{ST. ALBANS, TOWN OF}

MNUSS NeedID 100000000010166

Need Desc: Add streets to panel
CID 230369 MNUSS Summary

Date of Need: 9/17/1997

Panel: 230369 A

Length: $\odot \quad$ mi

Anticipated BFE Change: Not Applicable

Location of Floodplain:

Need Notes: THIS IS AN 11X17 AND WILL HAVE TO BE FORMATTED TO A Z-FOLD.

SPO Comments: See SPO B.A.D.-Great Moose Pd

MNUSS NeedID 100000000010166

Date of Need: $9 / 17 / 1997$

Panel: 230369 A

Need Desc: Add streets to panel

Length: $\odot \quad$ mi

Anticipated BFE Change: Not Applicable

Location of Floodplain:

Need Notes: THIS IS AN 11X17 AND WILL HAVE TO BE FORMATTED TO A Z-FOLD.

SPO Comments: DFIRM process will address 
EXISTING MNUSS ENTRIES FOR SOMERSET COUNTY

\section{ST. ALBANS, TOWN OF}

MNUSS NeedID 100000000010166

Need Desc: Add streets to panel
CID 230369 MNUSS Summary

Date of Need: 9/17/1997

Panel: 230369 A

Length: $\odot \quad$ mi

Anticipated BFE Change: Not Applicable

Location of Floodplain:

Need Notes: THIS IS AN 11X17 AND WILL HAVE TO BE FORMATTED TO A Z-FOLD.

SPO Comments: DFIRM process will address

MNUSS NeedID 100000000010181

Date of Need: 9/17/1997

MELON BROOK

Panel: 230369 A

Need Desc: Changes to BFEs

Length: $3.5 \mathrm{mi}$

Anticipated BFE Change: Increased By Greater Than 5 feet

Location of Floodplain:

Need Notes: THIS IS AN 11X17 AND WILL HAVE TO BE FORMATTED TO A Z-FOLD.

SPO Comments: See SPO B.A.D. 
EXISTING MNUSS ENTRIES FOR SOMERSET COUNTY

\section{ST. ALBANS, TOWN OF}

MNUSS NeedID 100000000010177

INDIAN STREAM

Need Desc: Changes to BFEs
CID 230369 MNUSS Summary

Date of Need: 9/17/1997

Panel: 230369 A

Length: 3 mi

Anticipated BFE Change: Increased By Greater Than 5 feet

Location of Floodplain:

Need Notes: THIS IS AN 11X17 AND WILL HAVE TO BE FORMATTED TO A Z-FOLD.

SPO Comments: See SPO B.A.D. 
Appendix E: Attachments 


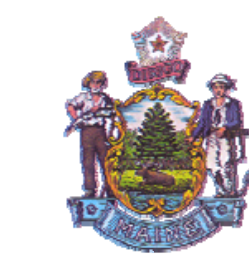

₹USGS

Tom Marcotte, Planner

Town of Skowhegan

225 Water Street

Skowhegan, Maine 04976

\section{STATE OF MAINE \\ EXECUTIVE DEPARTMENT \\ Maine State Planning Office \\ 38 State House Station \\ Augusta, ME 04333}

Subject: IMPORTANT MEETING - Flood Map Update - Scoping \& Data Collection for Somerset County

Dear Sir/Madam:

As part of their Flood Map Modernization initiative, the Maine Floodplain Management Program and the Federal Emergency Management Agency (FEMA) will be updating the Flood Insurance Rate Maps (FIRMs) for Somerset County communities and will be producing a County-wide digital FIRM (DFIRM). In an effort to share information on the flood map update process and provide an opportunity for local input, we would like to meet collectively with all the floodplain management officials (code enforcement officers and (or) planning board chairs) from the Somerset County communities. We hope for active participation at the meeting, which will help us establish the scope of the mapping project for Somerset County. Your community's input is very important if you wish to contribute to improving the flood maps. If you choose not to provide input, a new map will still be generated but may or may not reflect changes you would have liked. To accommodate local officials who may not be available for a daytime meeting, an evening meeting has been scheduled.

\section{Somerset County: Skowhegan Community Center, Thursday, November 3rd, 6-8 p.m.}

The State of Maine Floodplain Management Program, the US Geological Survey (USGS) and FEMA or its representative will conduct the scoping meeting. The purpose of the scoping meeting is to:

Inform the communities of the nature and the intent of the flood map update process and new digital product,

Make introductions and establish points of contact between the communities, the State of Maine Floodplain Management Program, USGS, and FEMA,

Break into small groups and solicit community input regarding community concerns with the current mapping of the special flood hazard areas (i.e., areas where there is a need for flood elevation data, areas that never flood but are currently mapped in the floodplain and vice versa),

[Note: the majority of current problems with the base map, such as lack of roads and labelling

errors, will be resolved due to use of new aerial photo and digital base map, as explained below]

Identify and prioritize problem areas on current maps (copies will be supplied), 
Discuss and record the availability of any community specific data:

O digital orthophotography and (or) topographic mapping data undertaken by the community,

0 local flood hazard studies undertaken by the developers, property owners or the community for permitting purposes as required in the local floodplain ordinance OR for the purposes of obtaining a Letter of Map Amendment/Letter of Map Revision from FEMA, any of which provides flood elevation data,

o verified historical data from past flooding events such as surveyed high water marks, photos taken at the time of high water, or post-disaster documents,

0 any community plans for, or interest in, acquiring or contributing to new data

Discuss any changes that have been made to hard structures (culverts, bridges, dams, etc.) within the community that may affect water flow/flooding, or any proposed large developments in the floodplain,

The updated Flood Insurance Rate Maps (FIRMs) will be in a county-wide inclusive format (with many panels), and will be produced in a digital format, known as a DFIRM. The DFIRM will also include an extensive GIS database, and the digital floodplain boundaries will be depicted on an aerial photo base map. The truly digital product will be able to be overlaid on existing GIS base maps of the community/county (i.e. tax map, shoreland zoning map, infrastructure or other GIS based maps), which will improve the use of flood hazard data at the local and regional level. Also, using the new flood map in either paper form or with GIS, will definitely allow for easier and faster flood map determinations.

It is very important that a representative(s) of your community attend the Scoping Meeting (the lead floodplain management person - usually the code enforcement officer, the planning board chair/planner, GIS staff, public works director and any interested elected official). It is also important that information regarding the time and place of the Scoping Meeting be disseminated so that anyone that could provide engineering, topographic and mapping data and is interested in the mapping results can attend.

To prepare for the Scoping Meeting, we would like for your community to identify flood mapping issues that you would like to be considered for (re)study or review. It would be helpful to have the flooding issues prioritized and be prepared to precisely locate the areas of concern on the flood maps at the meeting. In addition, it would also be very beneficial to bring a brief narrative describing the reasons for the requested (re)studies or reviews. This information will help facilitate the meeting and assist us in finalizing the scope of work. This information may also be sent to the lead scoping agency working in collaboration with the Maine Floodplain Management Program and FEMA: USGS, 196 Whitten Road, Augusta, ME 04330.

Attached with this letter please find a Scoping Meeting agenda and a fax-back sign-up form. Please submit the fax-back form by November 1, 2005 so that we can plan accordingly. Your prompt attention to this matter is appreciated, and will help ensure that an accurate and efficient project scope for the flood hazard mapping update for Somerset County is developed. If you have any questions regarding this Scoping Meeting or desire additional information, please feel free to contact Bonnie at (207) 287-8052 or Rob Dudley, from USGS, at (207) 622-8201 xtn 115.

Bonnie Cowle, CFM

Maine Map Modernization Project Coordinator

Maine Floodplain Management Program
G. Fred Vanderschmidt IV, CFM

FEMA Region I

Rob Dudley, P.E. 
USGS Maine Water Science Center

\begin{tabular}{|c|c|}
\hline \multicolumn{2}{|c|}{ FEMA Map Mod Scoping Meeting Agenda: Somerset County, Maine } \\
\hline \multirow{2}{*}{\multicolumn{2}{|c|}{$\begin{array}{l}\text { Meeting Date: 11/3/05 } \\
\text { Time: 6-8 P.M. }\end{array}$}} \\
\hline & \\
\hline \multirow{2}{*}{\multicolumn{2}{|c|}{$\begin{array}{l}\text { Location of Meeting: } \\
\text { Skowhegan Community Center }\end{array}$}} \\
\hline & \\
\hline Agenda Items & Estimated Time \\
\hline 1. Welcome and Introductions - Bonnie Cowle - State Planning Office & 5 minutes \\
\hline 2. Overview of Scoping Meeting Agenda & 5 minutes \\
\hline \multicolumn{2}{|l|}{ 3. Map Modernization Overview } \\
\hline Stuart Rooney - FEMA Representative from Watershed Concepts & 5 minutes \\
\hline Bonnie Cowle - SPO, Maine Floodplain Management Program & 5 minutes \\
\hline 4. Flood Mapping Schedule and Process & 5 minutes \\
\hline \multicolumn{2}{|l|}{ Bonnie Cowle - Schedule } \\
\hline 5. Map Details - Rob and Bonnie & 10 minutes \\
\hline $\begin{array}{l}\text { Discussion of specific DFIRM issues: } \\
\text { Map data layers } \\
\text { Various levels of map detail } \\
\text { New appearance of DFIRM } \\
\text { o } \quad \text { MEGIS orthophoto quad } \\
0 \quad \text { Scale and paneling scheme } \\
\text { o } \quad \text { Map adoption } \\
\text { What we need from you }\end{array}$ & \\
\hline 6. Breakout Sessions to Identify Community Mapping Needs & $60-90$ minutes \\
\hline $\begin{array}{l}\text { In small working groups with assigned leader: } \\
\text { Review and comment on USGS/SPO data sheet for your comm } \\
\text { With input from leader complete the community interview forn } \\
\text { o Discuss mapping update needs for each community } \\
\text { o Provide rationales for each update needed } \\
\text { On flood maps, highlight specific areas of need and indicate pri }\end{array}$ & ities \\
\hline 7. Turn in Forms \& Maps & \\
\hline Speakers will be available for any final questions & \\
\hline
\end{tabular}




\section{Somerset County Community Interview Form \\ FEMA Map Modernization Program \\ November 3, 2005}

\begin{tabular}{cc}
\hline Community: & \\
CID\#: & $230 \_-\ldots$ GOVT: $\square$ Town OR $\square$ council \\
& If Town Government, Date of Annual Town Meeting:
\end{tabular}

Community Representative(s) attending meeting:

Name(s):

Title(s):

Tel:

Email(s):

Fax:

Floodplain Mgt Community Contact (and contact info if different from above):

Known problems with flood maps for your community (note FIRM panel numbers)

(Note: Most base-map issues such as street names, roads, corporate boundaries, and spatial issues will be fixed when new digital FIRMS are produced) PLEASE PROVIDE ADDITIONAL INFORMATION FOR ANY YES ANSWERS BELOW

Do you have specific areas that don't flood (1\% chance) but are currently in the floodplain? $\square$ Yes $\square$ No

Do you have specific areas that flood (1\% chance) but are not mapped in the floodplain or not mapped at all? $\square$ Yes $\square$ No

Have any changes in hydraulic structures (bridges, culverts, dams) taken place that would change the maps? $\square$ Yes $\square$ No

Do you currently have (or are you proposing) high-development areas where you need new or restudied flood elevations or improved map scale? $\square$ Yes $\square$ No

\section{Community resources:}

Do you have aerial photography or plans for any (flight date, scale, color/black \& white)? $\quad \square$ Yes $\square$ No

Do you have topographic data or plans for collecting any (digital terrain, contour maps)? $\quad \square$ Yes $\square$ No

Do you have any other data like special hydrologic/hydraulic studies (or plans for studies)? $\quad \square$ Yes $\square$ No

Do you have dedicated GIS capabilities? $\square$ Yes $\square$ No (Provide GIS contact info if different from front page)

Interviewer: Review MNUSS entries and BAD with community rep.

NOTES: 